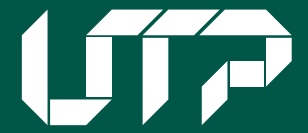

Universidad Tecnológica de Pereira

\title{
Perfil del cliente de los gimnasios y centros de acondicionamiento físico caso Pereira
}

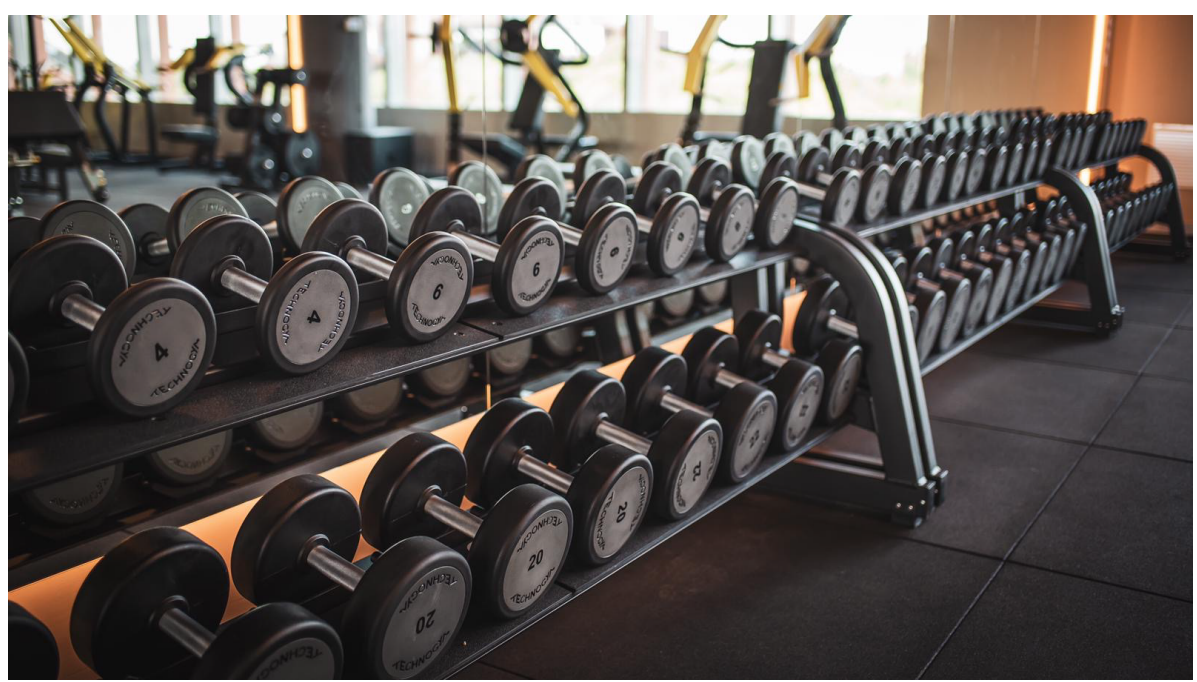

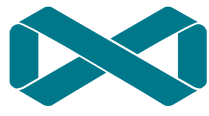

Editorial UTP
Ángela Jasmín Gómez Hincapié Carlos Danilo Zapata Valencia Claudia Patricia Cardona Triana Roberto Millán Gaviria Jerónimo García Fernández 
Ángela Jasmín Gómez Hincapié (Pereira, Risaralda, Colombia, 1972)

Especialista en Dirección y Gestión del Deporte, Magister en Gerencia del Talento Humano, Profesional en deporte en ciencias del deporte y la recreación.

Profesora asociada - facies

Coautora del libro Derecho Deportivo Colombiano (2010)

Pertenece al grupo de investigación Cultura De La Salud

jasmin19@utp.edu.co

Carlos Danilo Zapata Valencia, (Belén de Umbría, Risaralda, Colombia,1959).

Magister en Desarrollo Humano y Organizacional, Profesional en Deporte y Actividad Física.

Profesor titular - Facies

Autor de los libros : Manual De Promoción De La Actividad Física En Risaralda Tomo I (2006), Manual De Promoción De La Actividad Física En Risaralda Tomo II (2006) y Riesgo Cardiovascular en docentes y administrativos de la Universidad Tecnológica de Pereira (2010).

Pertenece al grupo de investigación Cultura de la Salud cazapata@utp.edu.co

Claudia Patricia Cardona Triana, (Santa Rosa de Cabal, Risaralda, Colombia ,1977)

Magister en Administración del Desarrollo Humano y Organizacional y Profesional en Ciencias del Deporte y la Recreación, Universidad Tecnológica de Pereira.

Docente Asociada en la Facultad Ciencias de la Salud.

Ha publicado artículos en revistas especializadas nacionales e internacionales.

Miembro del Grupo de investigación Cultura de la Salud.

claudiacardona@utp.edu.co

Roberto Millán Gaviria (Pereira, Risaralda, Colombia, 1969)

Especialista en Gerencia del Deporte, Magister en Derecho Deportivo Internacional, Especialista y Magister en Derecho Administrativo, Abogado Universidad Libre.

Docente asistente FACIES

Autor del libro Derecho Deportivo Colombiano (2010)

Miembro del Grupo de investigación Cultura De La Salud

robermillang@utp.edu.co

Jerónimo García Fernández. (España, 1979)

Licenciado en Ciencias de la Actividad Física y el Deporte, Doctor en Ciencias del Deporte por la Universidad de Sevilla.

Profesor Titular de la Universidad de Sevilla.

Ha publicado artículos en revistas especializadas nacionales e internacionales

Miembro del Grupo de Investigación SEJ525-Gestión e Innovación en Servicios Deportivos, Ocio, Recreación y Acción Social. Universidad de Sevilla (España). 


\title{
Perfil del cliente de los gimnasios y centros de acondicionamiento físico caso Pereira
}

\author{
Ángela Jasmín Gómez Hincapié \\ Carlos Danilo Zapata Valencia \\ Claudia Patricia Cardona Triana \\ Roberto Millán Gaviria \\ Jerónimo García Fernández
}

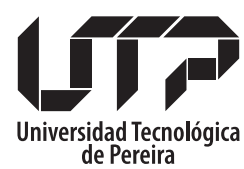

Facultad de Ciencias de la Salud

Colección Trabajos de Investigación 2019 
Gómez Hincapié, Ángela Jasmín

Perfil del cliente de los gimnasios y centros de acondicionamiento

físico caso Pereira / Ángela Jasmín Gómez Hincapié y otros. --

Pereira : Universidad Tecnológica de Pereira, 2019.

93 páginas. - (Colección Trabajos de investigación).

ISBN: 978-958-722-402-3

1. Ejercicio físico 2. Orientación deportiva 3. Gimnasio deportivo Pereira (Risaralda) 4. Instalaciones deportivas 5. Perfil de usuarios Gimnasios - Pereira (Risaralda)

CDD 796.4068

Perfil del cliente de los gimnasios y centros de acondicionamiento físico caso Pereira

(C) Ángela Jasmín Gómez Hincapié

(c) Carlos Danilo Zapata Valencia

(c) Claudia Patricia Cardona Triana

(C) Roberto Millán Gaviria

(C) Jerónimo García Fernández

(C) Universidad Tecnológica de Pereira

Primera edición, 2019

Proyecto de investigación: El Perfil del cliente de los gimnasios y centros de acondicionamiento físico caso Pereira, código 5-16-1

ISBN Obra independiente: 978-958-722-402-3

Universidad Tecnológica de Pereira

Vicerrectoría de Investigaciones, Innovación y Extensión

Editorial Universidad Tecnológica de Pereira

Pereira, Colombia

Coordinador editorial:

Luis Miguel Vargas Valencia

luismvargas@utp.edu.co

Teléfono 3137381

Edificio 9, Biblioteca Central "Jorge Roa Martínez"

Cra. 27 No. 10-02 Los Álamos, Pereira, Colombia

www.utp.edu.co

Montaje y producción:

Maria Alejandra Henao Jiménez

Recursos Informáticos y Educativos CRIE

Universidad Tecnológica de Pereira

Reservados todos los derechos 


\section{AGRADECIMIENTOS}

Agradecemos muy especialmente, a los gerentes de los gimnasios que accedieron a participar de la presente investigación y que aportar su voluntad, conocimientos, experiencia y la información de sus instituciones para llevar a buen término este trabajo.

Al grupo de investigación cultura de la salud en su línea GIGEDE, en especial a Oscar por su liderazgo, disciplina, rigurosidad, colaboración y compromiso.

A la Universidad de Sevilla, que representada por su docente Jerónimo Garcia, nos aportó su experiencia, experticia y conocimiento para avanzar por el camino correcto en este arduo trabajo.

A los honorables miembros del Consejo de Facultad de Ciencias de la salud, por su permanente e incondicional apoyo en cada una de las etapas de este proyecto de investigación, que hoy entrega sus frutos.

A las directivas de la Universidad Tecnológica de Pereira, por su respaldo institucional, logístico, financiero y administrativo, características que hacen de nuestra alma mater una entidad de calidad en todos sus procesos. 


\section{TABLA DE CONTENIDO}

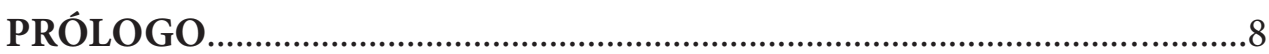

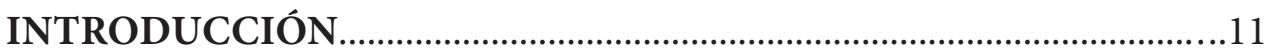

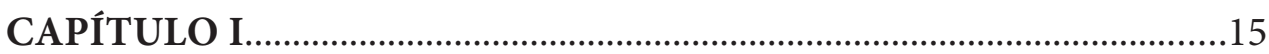

Capítulo I. Marco referencial de la investigación................................16

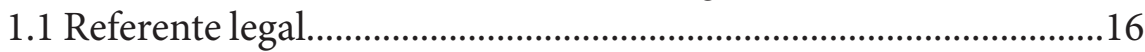

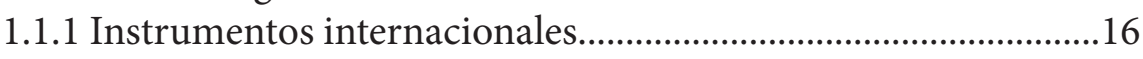

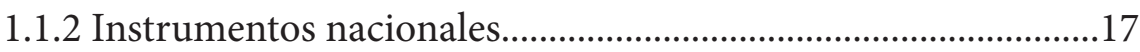

1.1.3 Resoluciones del ministerio de salud y protección

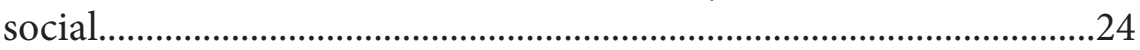

1.1.4 Documentos contentivos de políticas pública

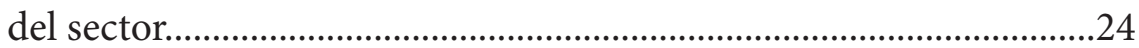

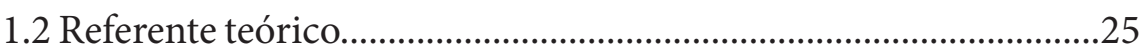

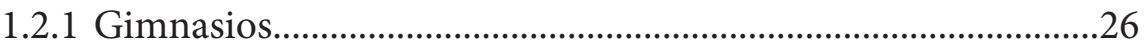

1.2.2 Centros de acondicionamiento y preparación física.................27

1.2.3 Calidad de equipamiento e instalaciones....................................28

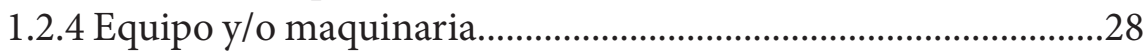

1.2.5 Calidad de los programas y servicios.......................................29

1.3. Segmentación de centros deportivos...............................................32

1.3.1 Importancia de la segmentación................................................33

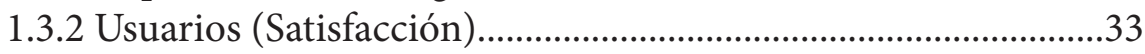

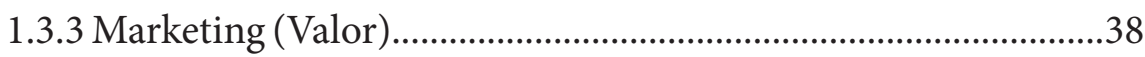

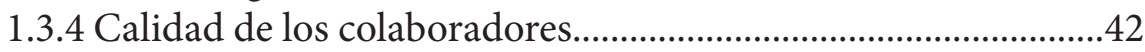

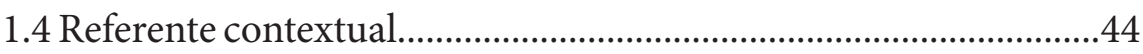

1.4.1 Caso colombiano "Centros Fitness en Pereira”............................44

1.4.2 Características Generales de los Gimnasios

y CAPF de Pereira.................................................................................4

CAPÍTULO II...............................................................................................5

Capítulo II. Metodología y resultados de la investigación..................58

2.1 Metodología...................................................................................58

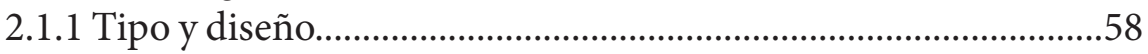

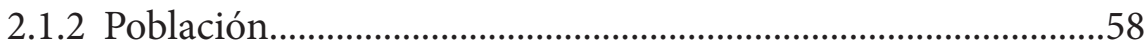

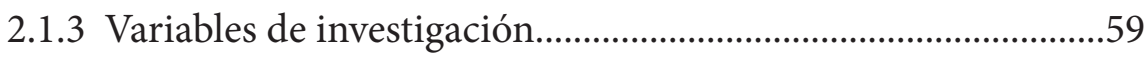




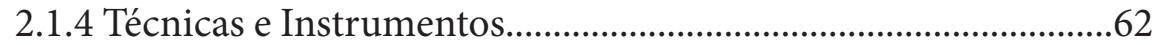

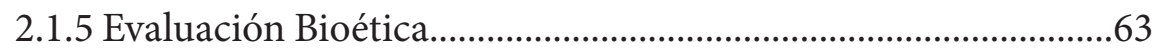

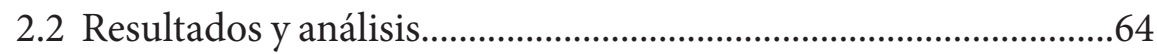

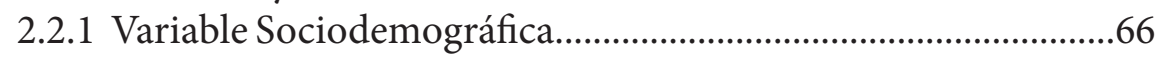

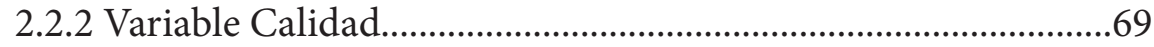

2.2.3 Análisis general de la variable calidad........................................72

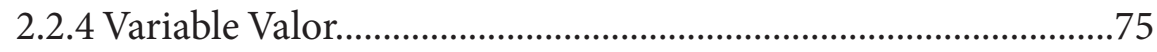

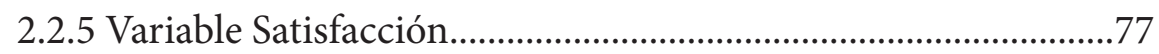

2.2.6 Variable intención de compra.....................................................78

\section{CAPÍTULO III}

Capítulo III. Conclusiones y recomendaciones de la investigación...

3.1 Conclusiones. 82

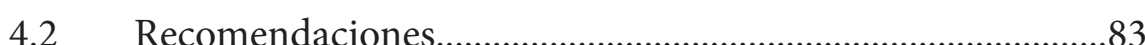

BIBLIOGRAFÍA. .85

ANEXOS. .91

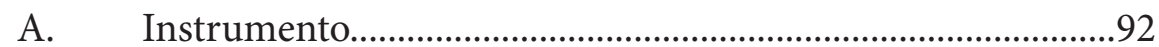

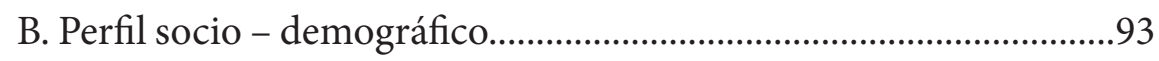




\section{Listado de figuras}

Figura 1. El proceso de Marketing.......................................................................40

Figura 2. Zona de Máquinas Gimnasio Spinning Center Gym

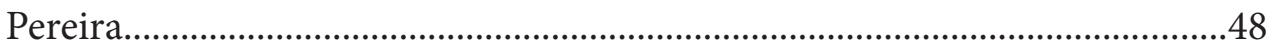

Figura 3. Gimnasio Atenas Gym Fitness.......................................................50

Figura 4. Logo del Gimnasio Sport Life Gym..................................................51

Figura 5. Logo e Instalaciones Gimnasio Ares Gym Pereira...........................55

Figura 6. Entrada del gimnasio Skandinavia.................................................56

Figura 7. Usuarios de gimnasios y centros de acondicionamiento físico según frecuencia de asistencia. Pereira, 2017.

Figura 8. Usuarios de gimnasios y centros de acondicionamiento

físico según duración de la sesión de entrenamiento. Pereira, 2017.

Figura 9. Usuarios de gimnasios y centros de acondicionamiento

físico según actividades que realiza. Pereira, 2017

Figura 10. Usuarios de gimnasios y centros de acondicionamiento

físico según calidad de las instalaciones. Pereira, 2017

Figura 11. Usuarios de gimnasios y centros de acondicionamiento

físico según calidad de los empleados. Pereira, 2017. .70

Figura 12. Usuarios de gimnasios y centros de acondicionamiento

físico según calidad de los programas. Pereira, 2017

Figura 13. Usuarios de gimnasios y centros de acondicionamiento

físico según calidad general de los programas y servicios.

Pereira, 2017

Figura 14. Usuarios de gimnasios y centros de acondicionamiento

físico según valor del servicio. Pereira, 2017.

Figura 15. Usuarios de gimnasios y centros de acondicionamiento ísico según satisfacción. Pereira, 2017

Figura 16. Usuarios de gimnasios y centros de acondicionamiento físico según intención de compra. Pereira, 2017. 


\section{Listado de tablas}

Tabla 1. Distribución de los participantes según género, edad, formación académica, ocupación, estado civil y rango salarial .64

Tabla 2. . Usuarios de gimnasios y centros de acondicionamiento

físico según frecuencia de asistencia. Pereira, 2017.

Tabla 3. Usuarios de gimnasios y centros de acondicionamiento

físico según duración de la sesión de entrenamiento. Pereira, 2017

Tabla 4. Usuarios de gimnasios y centros de acondicionamiento

físico según calidad de las instalaciones. Pereira, 2017

Tabla 5. Usuarios de gimnasios y centros de acondicionamiento

físico según calidad de los empleados. Pereira, 2017

Tabla 6. Usuarios de gimnasios y centros de acondicionamiento

físico según calidad de los programas. Pereira, 2017

Tabla 7. Usuarios de gimnasios y centros de acondicionamiento físico según calidad general de los programas y servicios.

Pereira, 2017.

Tabla 8. Usuarios de gimnasios y centros de acondicionamiento

físico según valor del servicio. Pereira, 2017 .75

Tabla 9. Usuarios de gimnasios y centros de acondicionamiento

físico según satisfacción. Pereira, 2017

Tabla 10. Usuarios de gimnasios y centros de acondicionamiento

físico según intención de compra. Pereira, 2017 .78

\section{Listado de cuadros}

Cuadro 1. Variables de investigación. 


\section{PRÓLOGO}

El mercado deportivo se ha convertido en un área de desarrollo y servicio esencial para la sociedad. La evolución propia de la necesidad de adaptarse a la ciudadanía ha permitido desarrollar varios enfoques del concepto tradicional del deporte. No sólo hacia el ámbito federativo y competitivo sino también hacia la promoción de la actividad física y la salud, incluyendo además otros elementos como herramienta educativa y de integración social o como elemento recreativo y de promoción del ocio y el turismo. Estos ámbitos de influencia se han ido recogiendo en diversos informes como el de Helsinki o Vocasport (European Commission, 1999). El primero hace referencia al deporte como uno de los ámbitos de actividad que más afecta a los ciudadanos de la Unión Europea: más de la mitad practica regularmente una actividad deportiva y cerca de 2 millones de profesores y de voluntarios trabajan para los 700.000 clubes deportivos existentes en la Unión; y el segundo que en el mismo sentido lo presenta como un campo de actividad económica y social en auge que contribuye por ejemplo al mantenimiento y desarrollo de la salud física y mental de la población, en todos los ámbitos y etapas de la vida, al refuerzo de la ciudadanía como base para crear y operar un deporte asociativo, a la educación, dentro o fuera de la escuela, como una fuerza impulsora; a la Integración social de las poblaciones desfavorecidas o inmigrantes; además desde la perspectiva económica implica casi un millón de trabajadores en el ámbito de su actividad principal (más de 2 millones si incluimos otras actividades relacionadas), sin mencionar los 10 millones de voluntarios que asumen responsabilidades en los deportes.

Ahora bien, el informe que la Comisión presenta al Consejo Europeo empieza analizando los recientes cambios sufridos por el deporte en Europa, y en particular su comercialización cada vez mayor. Esta evolución ha tenido consecuencias positivas -el número de puestos de trabajo creados en el sector ha aumentado en un $60 \%$ en los diez últimos años-, pero puede también debilitar la dimensión social y educativa del deporte si los dirigentes deportivos no conceden suficiente atención a fenómenos como la proliferación del dopaje. 
A pesar de la magnitud del concepto deporte, y de la evidencia demostrada de los beneficios que aporta su práctica en los diversos ámbitos sociales, según datos de la OMS de 2017 a nivel mundial, el 23\% de los adultos y el 81\% de los adolescentes en edad escolar no se mantienen suficientemente activos. Queda, por tanto, un amplio trabajo por realizar y un amplio segmento de población potencial al que debemos ofrecer un servicio adecuado y adaptado a sus necesidades.

Centrándonos en el ámbito del deporte recreativo y de promoción de la actividad física podemos observar, según los datos facilitados por IHRSA (Asociación Internacional de Salud, Raqueta y Clubes Deportivos), que los ingresos de la industria del fitness a nivel global ascendieron en 2017 a 87,2 mil millones de dólares en todo el mundo, donde más de 200.000 gimnasios atendieron a 174 millones de usuarios. Estos datos esperanzadores, constatan un continuo crecimiento en su histórico, que nos permite visualizar un futuro de desarrollo y demanda de nuevos centros y modelos de negocio, que permitan ir poco a poco mejorando y ampliando las estadísticas de uso de instalaciones y práctica de actividad física por parte de la población.

Frente a esta situación, en Pereira, tenemos el gran reto de mejorar y profesionalizar un sector que requiere de una gestión adecuada tanto de sus procesos, productos y equipamientos, como de las relaciones con el personal y el propio usuario. Disponer de los conocimientos y las herramientas necesarias para alcanzar la excelencia en la prestación de los servicios para con nuestros clientes, se convierte en un requisito obligado que no podemos aplazar ni aparcar.

En este sentido, es reconocido a nivel mundial cómo valora positivamente el cliente poder interactuar con profesionales cualificados y formados tal y como indican las encuestas de tendencias fitness elaboradas por la ACSM (Colegio Americano de Medicina del Deporte).

Tenemos frente a nuestros ojos una oportunidad única de mejorar profesionalmente aprendiendo del contenido práctico y útil que nos ofrecen estas páginas, y poder trasladar todo el conocimiento que adquiramos leyendo este libro, a nuestros equipos, nuestras instalaciones y sobre todo a mejorar la experiencia de nuestros clientes y usuarios. 
Como decía un gurú de la empresa, la clave es marcar expectativas realistas a nuestros clientes, y luego no solo satisfacerlas, sino superarlas.

Aprovechemos esta gran obra que seguro va a superar nuestras expectativas.

Manel Valcarce CEO Consultoría Valgo 


\section{INTRODUCCIÓN}

La demanda del deporte está incrementándose en todos los países a nivel mundial. La literatura de gestión deportiva hace hincapié en variables que pueden determinar el consumo de productos y servicios deportivos. En este caso, la calidad y el valor de los servicios deportivos, así como, la satisfacción con estos, son variables decisivas para que los consumidores sigan comprando, ya que la calidad en los servicios se mide por la respuesta o percepción del cliente frente a la relación entre lo que recibe y lo que espera (Millán Caballero, Santana Lugones y Escoriza Martínez, 2016).

Por tanto, hablar de mercados y servicios es imposible hacerlo sin tener en cuenta a los clientes o usuarios. En ocasiones, se idean y diseñan servicios antes de identificar al cliente, creyendo que una buena campaña de marketing y comunicación, atraerá la atención de aquellos que estén interesados y se puedan captar (Perea, 2013).

Para mayor efectividad, los mercados estables realizan segmentaciones para entender mejor al consumidor, donde lo ideal es la combinación de diferentes segmentaciones (Alexandris, Douka, Papadopoulos, y Kaltsatou, 2008). Cabe anotar que las variables comportamentales son decisorias para la compra de servicios (Bouchet, Bodet, Bernache y Kada, 2011), porque con estas se pueden identificar también, diferentes grupos de población. Por lo demás, es importante tener en cuenta el perfil sociodemográfico, dado que permite caracterizar los tipos de clientes.

Los antecedentes investigativos refieren que la edad y el género, tienen alta incidencia al momento de elegir actividades deportivas. Aspectos como la diversión, competición, estética corporal, hacer amigos y el reconocimiento social, además de la salud, son los motivos de práctica más importantes, dónde los hombres prefirieron la diversión y la competición, mientras que las mujeres dan prioridad a la salud y la estética corporal como las razones más importantes para la elección de actividades deportivas (Casas, 2004).

Estas investigaciones han sido desarrolladas principalmente en España. En el contexto colombiano es incipiente su abordaje, lo que reviste especial importancia, porque los centros de acondicionamiento y preparación física 
(CAPFS) y los gimnasios son organizaciones que ofertan servicios a través del deporte, la recreación y la actividad física (Congreso de Colombia, 3 de diciembre del 2001). Fueron creados a partir de la ley 729 de 2001, con el objeto de mantener y/o mejorar la salud de los usuarios, mediante un servicio seguro y beneficioso, bajo la orientación de médicos especialistas en salud y actividad física, nutricionistas, fisioterapeutas y profesionales del deporte, entre otros (Díaz Sánchez, 2011).

No obstante, a pesar de que la reglamentación establece criterios mínimos para estos establecimientos comerciales, el nivel de cumplimiento es deficiente, por lo que en algunos casos los clientes o usuarios son los que ejercen la evaluación de la calidad y del servicio, aunque, en la mayoría de los casos, son los propietarios y administradores quienes según su criterio, determinan las características del servicio en cuanto a calidad de sus instalaciones, equipamientos, programas, talento humano y valor en términos económicos y valor como impronta de lo ofertado. Lo que en ocasiones no cumple con los estándares plantados por la normatividad y por la máxima autoridad en salud, Organización Mundial de la Salud.

La investigación que soporta este estudio, fue realizada por el grupo de investigación Cultura de la salud en la linea de "Gerencia del Deporte y la Recreación” (GIGEDE), de la Universidad Tecnológica de Pereira (Colombia). en alianza con el grupo de investigación en gestión, de la Universidad de Sevilla (España).

El objetivo de la investigación fue evaluar la percepción del cliente en cuanto a calidad, valor, satisfacción e intenciones futuras en centros de fitness de Pereira (Gimnasios) (Colombia), y segmentarlos por características sociodemográficas y diferencias entre ellos.

La población fue 2100 usuarios (1011 mujeres y 1089 hombres), de los gimnasios con más de 300 usuarios activos, estos centros fueron: Spinning Center Gym, Sport Gym, Atenas Gym Fitness, Sport Life Gym, Platinium Fitness, Ares Gym y Gimnasio Skandinavia.

Se utilizó un cuestionario con preguntas sobre la calidad y valor percibido, satisfacción e intenciones futuras de compra (fidelidad), además de las 
características sociodemográficas, el cual fue validado por el grupo de gestión y contextualizado para el caso colombiano por el grupo Cultura de la salud en la línea GIGEDE, mediante prueba piloto. Se realizó un análisis de fiabilidad y prueba t y ANOVA.

Los resultados muestran la realidad en la percepción de sus clientes, constituyéndose como una guía para los gimnasios y CAPF sobre el perfil sociodemográfico de sus clientes, de acuerdo con la percepción del servicio recibido. Esto les permite a los gerentes, orientarse en torno a las necesidades deportivas, sociales y primordialmente de salud de sus usuarios, para conseguir y mantener excelentes parámetros de servicio, relacionados con la actividad física y el cuidado personal.

Además, en el presente libro se dejan antecedentes investigativos para la ciudad, la región y el país, y a la vez se socializa información sobre las diferentes leyes y estatutos que rigen a estos establecimientos, de igual manera es un insumo para el ente deportivo municipal o distrital, a quien le corresponde (de acuerdo con la ley), velar por las adecuadas condiciones de salud, higiene y competencia del servicio deportivo prestado por estas organizaciones.

El presente libro está estructurado en tres capítulos. En el primero se encuentra el marco de referencia, contexto legal (artículos de la Constitución Política de Colombia, leyes, resoluciones y políticas públicas, que enmarcan y regulan la actividad física, los gimnasios y CAPFS). Marco teórico sobre gimnasios, CAPFS, segmentación de centros deportivos y marketing; también referencias teóricas sobre las variables abordadas en la investigación (calidad de equipamientos e instalaciones, calidad de los programas y servicios, satisfacción de usuarios, valor del servicio abordado desde el marketing y calidad de los colaboradores).

Para finalizar se trata el referente contextual de los gimnasios participantes en la investigación En el segundo capítulo, se trata el proceso metodológico utilizado en la investigación y los resultados. En el tercer capítulo se presentan las conclusiones y recomendaciones del estudio, como insumo para estos centros deportivos, otros de características similares y se dejan los antecedentes para estudios similares. 

CAPÍTULO I 


\section{CAPÍTULO I. MARCO REFERENCIAL DE LA INVESTIGACIÓN}

\subsection{REFERENTE LEGAL}

\subsubsection{INSTRUMENTOS INTERNACIONALES.}

La Carta Internacional de la educación física, la actividad física y el deporte, contempla en su artículo $1^{\circ}$, que "Todo ser humano tiene derecho a acceder a la educación física, la actividad física y el deporte sin discriminación alguna, ya esté está basada en criterios étnicos, el sexo, la orientación sexual, el idioma, la religión, la opinión política o de cualquier otra índole, el origen nacional o social, la posición económica o cualquier otro factor." (UNESCO, 2015)

Este instrumento internacional constituye una actualización al aprobado y adoptado por la $20^{\circ}$ Conferencia General de la Unesco (Organización de la Naciones Unidas para la Educación, Ciencia y Cultura) en el año 1978, enmendada en el año 1990.

Para la $38^{\circ}$ Conferencia General, este Organismo le incluyó el concepto de Actividad física, ausente en las dos primeras versiones del instrumento.

La Declaración de Berlín suscrita por los Ministros de la Mineps (Conferencia Internacional de Ministros y Altos Funcionarios Encargados de la Educación Física y el Deporte dela Unesco) contiene dos declaraciones de gran importancia para la promoción y fomento de la actividad física a nivel internacional.

La primera de ellas es la reafirmación de que "en muchos países los crecientes niveles de inactividad física tienen fuertes repercusiones en la prevalencia de enfermedades no transmisibles y en la salud general del conjunto de la población"

La segunda de ellas es el compromiso de los países miembros a "Invertir en el desarrollo comunitario y en infraestructuras accesibles para alentar la actividad física" (UNESCO, 2013). 


\subsubsection{INSTRUMENTOS NACIONALES.}

\subsubsection{CONSTITUCIÓN POLÍTICA DE COLOMBIA.}

El 4 de julio de 1991, se promulga una nueva Constitución en Colombia, fruto de las deliberaciones y decisiones de la Asamblea Nacional, elegida por voto popular (primera vez en la historia de esta nación).

En ella se adoptó el modelo de estado social, democrático y constitucional de derecho, en el cual el principio fundamental es la dignidad humana.

El catálogo de derechos y libertades es propio del nuevo modelo y en el capítulo de los derechos sociales se incluyó al Deporte y la Recreación.

Se establecen nuevos fines del estado, abandonando el esquema decimonónico francés, por uno nuevo, inspirado en la corriente jurídica denominada neo constitucionalismo.

Esta escuela de pensamiento jurídico, modifica el papel del juez en el orden social, al conferirle a las decisiones de los órganos de cierre, el carácter de fuente formal del derecho.

De allí la importancia de los fallos de la Corte Constitucional en su función de tutela de los derechos fundamentales.

En uno de esos trascendentales fallos, el máximo tribunal, determina que el deporte constituye un derecho fundamental autónomo, elevándolo de categoría y cubriéndolo de la garantía de la acción de tutela.

En materia de servicios de salud, se impone al estado, la obligación de organizar, dirigir y reglamentar la prestación de servicios médicos. Así mismo, establece las competencias de la Nación, las entidades territoriales y los particulares y determina la distribución de los recursos con los cuales se financia este sistema.

Finalmente, en su artículo 366 establece la norma que determina la obligación del estado de priorizar en su presupuesto de gastos, un rubro especial destinado 
a satisfacer las necesidades básicas de la población, denominado gasto público social. Dentro del texto constitucional se establece que la salud, el deporte y la recreación son beneficiarios de esta categoría presupuestal.

Para mayor claridad, se presentan algunas normas:

Artículo 2o.- Son fines esenciales del Estado: servir a la comunidad, promover la prosperidad general y garantizar la efectividad de los principios, derechos y deberes consagrados en la Constitución; facilitar la participación de todos en las decisiones que los afectan y en la vida económica, política, administrativa y cultural de la Nación; defender la independencia nacional, mantener la integridad territorial y asegurar la convivencia pacífica y la vigencia de un orden justo.

Artículo $26^{\circ}$.- Toda persona es libre de escoger profesión u oficio. La ley podrá exigir títulos de idoneidad. Las autoridades competentes inspeccionarán y vigilarán el ejercicio de las profesiones. Las ocupaciones, artes y oficios que no exijan formación académica son de libre ejercicio, salvo aquellas que impliquen un riesgo social. Las profesiones legalmente reconocidas pueden organizarse en colegios. La estructura interna y el funcionamiento de éstos deberán ser democráticos. La ley podrá asignarles funciones públicas y establecer los debidos controles.

Artículo 52: El ejercicio del deporte, sus manifestaciones recreativas, competitivas y autóctonas tienen como función la formación integral de las personas, preservar y desarrollar una mejor salud en el ser humano. El deporte y la recreación, forman parte de la educación y constituyen gasto público social. Se reconoce el derecho de todas las personas a la recreación, a la práctica del deporte y al aprovechamiento del tiempo libre. El Estado fomentará estas actividades e inspeccionará, vigilará y controlará las organizaciones deportivas y recreativas cuya estructura y propiedad deberán ser democráticas.

Artículo 78. La ley regulará el control de calidad de bienes y servicios ofrecidos y prestados a la comunidad, así como la información que debe suministrarse al público en su comercialización. Serán responsables, de acuerdo con la ley, quienes en la producción y en la comercialización de bienes y servicios, atenten contra la salud, la seguridad y el adecuado aprovisionamiento a consumidores 
y usuarios. El Estado garantizará la participación de las organizaciones de consumidores y usuarios en el estudio de las disposiciones que les conciernen. Para gozar de este derecho las organizaciones deben ser representativas y observar procedimientos democráticos internos. (Congreso de la República de Colombia, 1991).

\subsubsection{LEY 181 DE 1995.- CREACIÓN DEL SISTEMA NACIONAL DEL DEPORTE.}

Como consecuencia de la categorización del deporte y la recreación, surge la obligación del estado colombiano para crear normas de fomento, inspección y vigilancia para estas actividades.

La decisión del Congreso de la República, por iniciativa del ejecutivo, fue la promulgación de la ley 181 de enero 18 de 1995, que establece el sistema nacional. Se establece una estructura en la que sobresalen dos ramas; una pública y otra privada, así como la concurrencia de una serie de organizaciones que brindan asesoría y apoyo al sistema.

Las normas que sobresalen y se deben incluir en la presente obra, para una mejor comprensión de la materia, son:

Es pertinente consignar en el presente trabajo, el texto completo de las principales normas de esta ley:

Artículo 81. Las academias, gimnasios y demás organizaciones comerciales en áreas y actividades deportivas de educación física y de artes marciales, serán autorizados y controlados por los entes deportivos municipales conforme al reglamento que se dicte al respecto. Corresponderá al ente deportivo municipal o distrital, velar porque los servicios prestados en estas organizaciones se adecuen a las condiciones de salud, higiene y aptitud deportiva (Congreso de la República, 1995). 


\subsubsection{LEY 715 DE 2001 - NORMAS ORGÁNICAS SOBRE DISTRIBUCIÓN DE RECURSOS Y COMPETENCIAS.}

En el año 2001, ante la grave situación fiscal de los entes territoriales, se expidieron una serie de normas que modificaron el sistema de distribución de recursos y competencias entre la nación y los municipios y departamentos. En el campo de la salud, se asignó a los municipios, la vigilancia y coordinación del sector salud, en especial, sobre los establecimientos entre los que se encuentran los gimnasios.

\subsubsection{LEY 715 DE 2001.- COMPETENCIAS SECTORIALES: CAPÍTULO II, COMPETENCIAS DE LAS ENTIDADES TERRITORIALES EN EL SECTOR SALUD.}

Artículo 44. Competencias de los municipios. Corresponde a los municipios dirigir y coordinar el sector salud y el Sistema General de Seguridad Social en Salud en el ámbito de su jurisdicción, para lo cual cumplirán las siguientes funciones, sin perjuicio de las asignadas en otras disposiciones.

Artículo 44.3. De Salud Pública.

Artículo 44.3.5. Ejercer vigilancia y control sanitario en su jurisdicción, sobre los factores de riesgo para la salud, en los establecimientos y espacios que puedan generar riesgos para la población, tales como establecimientos educativos, hospitales, cárceles, cuarteles, albergues, guarderías, ancianatos, puertos, aeropuertos y terminales terrestres, transporte público, piscinas, estadios, coliseos, gimnasios, bares, tabernas, supermercados y similares, plazas de mercado, de abasto público y plantas de sacrificio de animales, entre otros.

Artículo 44.3.6. Cumplir y hacer cumplir en su jurisdicción las normas de orden sanitario previstas en la Ley 9a de 1979 y su reglamentación o las que la modifiquen, adicionen o sustituyan (Congreso de la República de Colombia, 21 de diciembre de 2001). 


\subsubsection{LEY 729 DE 2001: CENTROS DE CONDICIONAMIENTO Y PREPARACIÓN FÍSICA (CAPF).}

Los CAPFS o Centros de Acondicionamiento y Preparación Física se definen como: Establecimientos que prestarán un servicio médico de protección, prevención, recuperación, rehabilitación, control, y demás actividades relacionadas con las condiciones físicas, corporales y de salud de todo ser humano, a través de la recreación, el deporte, la terapia y otros servicios fijados por autoridades competentes y debidamente autorizados, orientados por profesionales en la salud, que coordinarían a licenciados en educación física, tecnológicos deportivos y demás personas afines que consideren que el tratamiento o rehabilitación de la personas se realice en los CAPF

Dentro de su articulado, esta ley ordena que tanto las instalaciones como los implementos a usar deben ser los necesarios y los adecuados para el debido desarrollo de las actividades requeridas para el buen servicio, e igualmente indica que los respectivos centros deberán estar previstos de "servicio médico, fisioterapéutico, nutricional y demás servicios que las autoridades soliciten para su funcionamiento" y todo su personal deberá estar altamente capacitado. (Congreso de la República, 2001)

\subsubsection{LEY 1801 DE 2016, CÓDIGO NACIONAL DE POLICÍA Y CONVIVENCIA.}

Regula algunas obligaciones generales para todos los establecimientos de comercio, relacionadas con el uso del suelo, la obligación de mantener vigente la matricula mercantil, autorizaciones para manejo y operación de equipos de comunicaciones, disposición y préstamo de servicios sanitarios, derechos de autor, por reproducción de piezas musicales, Para una mejor ilustración, se transcriben a continuación, estos requisitos y obligaciones:

Artículo 87. Requisitos para cumplir actividades económicas. Es obligatorio, para el ejercicio de cualquier actividad: comercial, industrial, de servicios, social, cultural, de recreación, de entretenimiento, de diversión; con o sin ánimo de lucro, o que siendo privadas, trasciendan a lo público; que se desarrolle o no a través de establecimientos abiertos o cerrados al público, además de los requisitos previstos en normas especiales, cumplir previamente a la iniciación de la actividad económica los siguientes requisitos: 
1. Las normas referentes al uso del suelo, destinación o finalidad para la que fue construida la edificación y su ubicación.

2. Mantener vigente la matrícula mercantil de la Cámara de Comercio de la respectiva jurisdicción donde se desarrolle la actividad.

3. La comunicación de la apertura del establecimiento, al comandante de estación o subestación de Policía del lugar donde funciona el mismo, por el medio más expedito o idóneo, que para tal efecto establezca la Policía Nacional.

4. Para la comercialización de equipos terminales móviles se deberá contar con el permiso o autorización expedido por el Ministerio de Tecnologías de la Información y las Comunicaciones o su delegado.

Durante la ejecución de la actividad económica deberá cumplirse con los siguientes requisitos:

1. Las normas referentes a los niveles de intensidad auditiva.

2. Cumplir con los horarios establecidos para la actividad económica desarrollada.

3. Las condiciones de seguridad, sanitarias y ambientales determinadas en el régimen de Policía.

4. El objeto registrado en la matrícula mercantil y no desarrollar otra actividad diferente.

5. Para aquellos establecimientos donde se ejecuten públicamente obras musicales causantes de pago, protegidas por las disposiciones legales vigentes sobre derechos de autor, mantener y presentar el comprobante de pago al día. Artículo 88. Servicio de baño. Es obligación de todos y cada uno de los establecimientos de comercio abiertos al público, prestar el servicio de baño a niños, mujeres en evidente estado de embarazo y adultos de la tercera edad cuando así lo soliciten, sin importar que los mismos sean sus clientes o no. La inobservancia de la presente norma tendrá como consecuencia la imposición de una Multa General Tipo 1 o suspensión temporal de actividad. 
Será potestad de los establecimientos de comercio en mención el cobro del servicio enunciado el cual deberá ser regulado por los correspondientes entes territoriales (Congreso de la República de Colombia, 2016).

Finalmente, y de reciente expedición, esta disposición ordena a los administradores de los gimnasios y CAPF a disponer de un Desfibrilador Externo Automático (DEA).

\subsubsection{LEY 1831 DE 2017. USO DEL DESFIBRILADOR EXTERNO AUTOMÁTICO EN LUGARES DE ALTA AFLUENCIA DE PÚBLICO.}

Artículo 10. Objeto. La presente ley tiene como objeto establecer la obligatoriedad, la dotación, disposición y acceso a los Desfibriladores Externos Automáticos (DEA) en los transportes de asistencia básica y medicalizada, así como en los espacios con alta afluencia de público.

Artículo 2. Definiciones. Para los efectos de la presente ley se entenderá por:

1. Desfibrilador Externo Automático (DEA). Aquel dispositivo medico electrónico portátil, dotado de electrodos destinados a generar y aplicar pulsos intensivos que puede descargar una corriente al corazón a través del tórax, para que esta detenga la fibrilación ventricular y permita que el corazón vuelva a un ritmo normal saliendo del paro, que garantice el ritmo cardiaco viable del paciente.

2. Transportes asistenciales. Son los transportes asistenciales básicos y medicalizados, tanto públicos como privados, de orden terrestre, fluvial, marítimo y aéreo, cuyo objeto es el traslado de los pacientes a los servicios de salud de conformidad con el requerimiento de atención en virtud de la patología o trauma padecido.

3. Espacios con alta afluencia de público. Son los espacios públicos y privados, abiertos o cerrados, permanentes o temporales, destinados a la recepción, atención, circulación o estancia de alta afluencia de público. 
Artículo $3^{\circ}$. Ámbito de aplicación. La presente ley estaba destinada a garantizar el acceso a Desfibriladores Externos Automáticos (DEA) en ambientes extrahospitalarios, transportes asistenciales y espacios con alta afluencia de público, tales como los siguientes:

c) Escenarios deportivos, tanto públicos como privados, tales como estadios, coliseos, polideportivos, canchas sintéticas, gimnasios, clubes deportivos, acuáticos y parques naturales, de diversiones o recreacionales, ciclovías y centros de alto rendimiento o entrenamiento (Congreso de la República de Colombia, 2 de mayo de 2017).

\subsubsection{RESOLUCIONES DEL MINISTERIO DE SALUD Y PROTECCIÓN SOCIAL.}

Resolución 001043 de 2006 dicha resolución hace referencia a las condiciones que deben cumplir los prestadores de servicios de salud para que sean habilitados para su funcionamiento. Se hace referencia a la presente resolución dado que los CAPFS son entidades que tienen un rol muy importante respecto a la salud de los usuarios, incluso cuando ellos no requieran servicios de rehabilitación, tratamiento, recuperación u otros; pues el eje central de estas entidades es la actividad física, lo que implica intervenir en la fisiología del cuerpo, por lo cual es de vital importancia conocer el metabolismo y afecciones físicas y fisiológicas de los asistentes, a fin de aplicar de la forma más adecuada la terapia a implementar con cada persona (Ministerio de Salud y Protección Social, 2006)

\subsubsection{DOCUMENTOS CONTENTIVOS DE POLÍTICAS PÚBLICAS DEL SECTOR.}

Plan Decenal del deporte, la recreación, la educación física y la actividad física 2009 - 2019 (COLDEPORTES, 2009). Dados los cambios de hábitos que se marcan con la evolución del tiempo se ha ido la transformando la forma de aprovechar el tiempo libre, a la vez se pone en riesgo la salud y el desarrollo integral humano, lo cual ha llevado a buscar nuevas formas de organización para el deporte, la recreación y la educación física y la actividad física creándose un Plan Decenal para dichas áreas. 
Para lograr esta nueva organización el Plan Decenal 2009-- 2019 estructuró 3 lineamientos, los cuales a su vez están compuestos por estrategias y objetivos que pretenden brindar un mayor estatus a este sector.

En este sentido, siendo los CAPFS establecimientos promotores de actividad física, deben acogerse a este plan procurando seguir los lineamientos, estrategias $\mathrm{y} / \mathrm{u}$ objetivos correspondientes a sus labores, como por ejemplo contar con el registro que se propone para instituciones públicas y privadas dando organización al sector, propuesta que se presenta en el lineamiento 1 (COLDEPORTES, 2006).

Política Pública de Deporte, Recreación, Actividad física y Educación Física (DRAEF) "Pereira activa, saludable e incluyente" 2012 - 2021. Basada en el mencionado plan decenal nace la política pública DRAEF "Pereira Activa, Saludable e Incluyente" 2012 - 2021, creada con el fin de aportar al logro de los objetivos propuestos en dicho plan desde las acciones del municipio de Pereira, se compone de 3 lineamientos básicos: $1^{\circ}$ ) Organización y Fortalecimiento Institucional del Sector, $2^{\circ}$ ) Promoción y Fomento de la Recreación, la Educación Física, la Actividad Física y el Deporte, $3^{\circ}$ ) Posicionamiento y Liderazgo Deportivo. Al tratarse de temas directamente relacionados con la actividad física, la recreación y el deporte, se hace indispensable que los CAPFS atiendan lo más pronto posible a las labores correspondientes, contribuyendo a la organización del municipio, el departamento y por ende del país.

\subsection{REFERENTE TEÓRICO}

En Colombia los centros de acondicionamiento físico se entienden como gimnasios, los cuales son establecimientos en donde las personas se reúnen para realizar actividad física, entrenamiento con máquinas o simplemente por estética, cada una con un objetivo similar o diferente, es por ello indispensable que en un gimnasio se cuente con el equipamiento, las instalaciones, los programas y el talento humano adecuado para suplir cada una de las necesidades de los usuarios, garantizando su satisfacción y permanencia en el mismo. 


\subsubsection{GIMNASIOS.}

Durantelas últimas décadas seha ido comprobandolosbeneficiosinnumerables de la actividad física, siendo respaldadas por pruebas científicas, logrando aumentar el ejercicio físico y los hábitos de vida saludable, mejorando la calidad de vida y disminuyendo una serie de amenazas para la salud que trae consigo la inactividad física y el sedentarismo, por tal razón las personas han visto la necesidad de acudir a sitios especializados donde puedan realizar las actividades pertinentes, guiadas, vigiladas y controladas por los profesionales en el área de la salud.

El ejercicio físico y los hábitos de vida saludable, mejorando la calidad de vida y disminuyendo una serie de amenazas para la salud que trae consigo la inactividad física y el sedentarismo, por tal razón las personas han visto la necesidad de acudir a sitios especializados donde puedan realizar las actividades pertinentes, guiadas, vigiladas y controladas por los profesionales en el área de la salud.

De otra parte, Coelho (2004) señala que el gimnasio se originó en la antigua Grecia y se trataba de un lugar público para practicar actividad física, como mecanismo de rendir culto al cuerpo y mantener la salud, aunque los griegos los utilizaban también para el desarrollo de otras actividades de intercambio sociocultural (cit en. Solar, 2003).

Desde esta perspectiva, en la era moderna donde aparece el sedentarismo, que se asocia a la falta de realización de actividad física, y más aun con el desarrollo de los aparatos tecnológicos, se evidencia más que las personas estén sometidas a la falta de ejercicio físico en pro de mejorar su salud; pero debido al gran auge en los últimos años que tienen los gimnasios y el porqué de la gran afluencia de personas a estos, se ha logrado ganar terreno en cuanto a la práctica de actividad física regular, donde las características, el servicio y la forma como se lleve a cabo el manejo con el usuario es lo que permite que las personas mantengan estas prácticas saludables en su vida diaria (Díaz Sánchez, 2011).

Los gimnasios se han ido convirtiendo en lugares y/o centros fundamentales para la salud de las personas, siempre y cuando cumplan con los requerimientos que se le debe brindar a los usuarios, tanto técnicos como administrativos, 
buscando el bienestar físico y psicológico de los mismos, logrando con esto un funcionamiento adecuado y óptimo de los centros.

\subsubsection{CENTROS DE ACONDICIONAMIENTO Y PREPARACIÓN FÍSICA.}

Los CAPF se crearon para satisfacer las necesidades que día a día le va surgiendo al hombre en la actualidad, cada persona trae consigo uno o varios objetivos, ya sea el mejoramiento de la estética corporal, liberarse del estrés y la ansiedad, obtener los beneficios de la actividad física o simplemente por salud, por ende, buscan ser orientados por profesionales en el campo, quienes con su experiencia y conocimiento logren satisfacer las necesidades individuales de cada usuario. Entre las instituciones que prestan servicios deportivos en Colombia se encuentran los CAPF, la ley 729 de 2001 los define como:

Establecimientos que prestarán un servicio médico de protección, prevención, recuperación, rehabilitación, control, y demás actividades relacionadas con las condiciones físicas, corporales y de salud de todo ser humano, a través de la recreación, el deporte, la terapia y otros servicios fijados por autoridades competentes y debidamente autorizados, orientados por profesionales en la salud, que coordinarían a licenciados en educación física, tecnólogos deportivos y demás personas afines que consideren que el tratamiento o rehabilitación de la persona(s) se realice en los CAPF.

En estos establecimientos se realizan acciones tales como:

- Elaboración y ejecución de programas y prescripción de actividad física

- $\quad$ Evaluación del estado de salud de las personas y recomendaciones específicas para cada caso

- Dirección, control y seguimiento de las actividades físicas de cada persona

- Asesoría profesional de primera calidad que aclara y resuelve todo tipo de inquietudes en cuanto a ejercicio físico, tratamiento, nutrición y rehabilitación, enmarcando todo el campo de la salud. (Congreso de la República de Colombia, 31 de diciembre de 2001). 


\subsubsection{CALIDAD DE EQUIPAMIENTO E INSTALACIONES.}

En cuanto a la clasificación y tipología de las instalaciones deportivas, Reverter y Barbany (2007) realizaron una clasificación según el equipamiento que tienen y los objetivos que persiguen. Entre ellas están:

- Centros de salud y fitness (health \& fitness centers). Son las instalaciones deportivas de explotación del fitness y de recreo, de ejercicio, de acondicionamiento físico y actividades deportivas recreativas.

- Gimnasio. Espacio físico destinado a la práctica de deporte. Para ello es posible que dispongan de sala de musculación, sala cardiovascular, sala de artes marciales y de aeróbic (Reverter \& Barbany, 2007).

- $\quad$ Centros de fitness. Espacios en donde se "plantea la necesidad de contar (...) con profesionales de la actividad física, asesorados por un médico especialista en medicina deportiva, los cuales sean garantes de una buena orientación del ejercicio". (Vallejo, 2005, p. 22).

- $\quad$ Fitness center. Es el centro que aplica el conjunto de técnicas físicas, psicológicas y sociales que aseguran la salud individual y por ende la salud social (Reverter y Barbany, 2007).

- $\quad$ Centro fitness \& Wellness. Es el centro que aplica el conjunto de técnicas físicas, psicológicas y sociales que aseguran la calidad de vida de sus clientes, entendiendo calidad de vida como un concepto multidimensional que incluye todos los ámbitos de la vida humana como la salud, el disfrute, el relax o el bienestar (Reverter y Barbany, 2007).

\subsubsection{EQUIPO Y/O MAQUINARIA.}

Las máquinas y el equipamiento son uno de los factores indispensables dentro de un gimnasio, ya que la variedad y de su calidad depende en gran parte la satisfacción y el interés de los usuarios y su permanencia en el gimnasio. 


\section{Clasificación De Equipos}

- Peso Libre: Trabaja grandes grupos musculares, involucrando un esfuerzo superior, puesto que requiere que el cuerpo se posicione correctamente, controle y determine el recorrido que se realiza en cada ejercicio, los pesos que se pueden encontrar son mancuernas, barras, sistemas de poleas ajustables, balones medicinales y el mismo cuerpo humano.

- Poleas: Dispositivo mecánico de tracción que sirve para transmitir una fuerza, Su función es reducir el esfuerzo físico para movilizar el peso, hay poleas estáticas que ya cumplen una función a nivel muscular, ejemplo la polea alta para el trabajo de espalda o poleas ajustables, que se gradúan según la necesidad del trabajo muscular.

- $\quad$ Hammer: Soporte de alta resistencia, que utiliza las leyes físicas de las palancas con la que se puede individualizar por hemisferios derecho o izquierdo la fuerza, lo que se conoce como trabajo de hipertrofia que permite el desarrollo y estimulación del músculo igual en ambas extremidades, al usar la misma carga.

- $\quad$ Equipos funcionales: funcionales: Son los diferentes instrumentos que se utilizan para trabajar con alguna resistencia y que se adaptan fácilmente a algún deporte o actividad, permitiendo realizar movimientos en diferentes planos, en ella se hace un trabajo con implementación mixta, usando, balones medicinales, cajones pliométricos (plio box), pesas rusas o campanas (kettlebell o KB), ruedas o llantas, sistemas de suspensión, cuerdas o ropes, mancuernas, barras, sacos de arena (sandbag).

\subsubsection{CALIDAD DE LOS PROGRAMAS Y SERVICIOS.}

Cada gimnasio y/o centro de acondicionamiento físico tiene la libertad de elegir y promocionar los diferentes programas y servicios que deseen ofrecerles a los usuarios, logrando con estos captar la atención y el interés de las personas interesadas en hacer parte de dicho establecimiento, impactando a la comunidad y sociedad en general, mostrando variedad e innovación en todas las áreas planteadas en los programas a ofrecer. 
Actualmente el ejercicio físico dentro del gimnasio no ha tenido una rigurosidad en la estructuración. Muchos son los motivos que sustentan tal afirmación: falta de equipos para las diferentes valoraciones, capacitación insuficiente, altos costos para evaluar a todos los usuarios, entre otros. Esto acarrea gran parte de la deserción a la que se ven sometidos un alto porcentaje de gimnasios, debido a que los objetivos por los cuales ingresan los usuarios a este lugar no son logrados, y es precisamente la falta de una adecuada prescripción a partir de una valoración individual lo que permite la consecución de los resultados, algunos como reducción de tejido graso, aumento de masa muscular, mejora de la capacidad aeróbica, etc. Se evidencia entonces la falta de evaluación de la composición corporal y por ende el desconocimiento del estado actual de las capacidades físicas de cada persona, y el efecto directo en la consecución de los objetivos trazados, siendo más peligroso la ejecución inadecuada del ejercicio físico porque puede acarrear problemas de salud, por no tener una adecuada prescripción, ni programación acorde a las necesidades de cada individuo. (Gutiérrez Macías, 2004)

Los servicios de los gimnasios y los centros de acondicionamiento y preparación física se definen como un conjunto de actividades que buscan responder y satisfacer las necesidades de los usuarios.

Los programas prestados son:

- $\quad$ Médicos

- $\quad$ Fisioterapia

- Nutrición

- $\quad$ Entrenamiento dirigido

Los servicios prestados son:

- $\quad$ En talento humano: asesoramiento, valoración médica, prescripción nutricional y médica, fisioterapia, prescripción del ejercicio.

- $\quad$ En las instalaciones: vestier, casilleros, parqueaderos, sala de espera, zona wifi, televisores, zonas húmedas (duchas, turco, baños), recepción, ascensor, sala de clases grupales, sala de máquinas, sala de entrenamiento funcional, sala de valoración médica, sala de fisioterapia y sala de nutrición. 


\section{Generalidades de los servicios:}

- $\quad$ Evaluación de la composición corporal, allí se analizan diferentes componentes corporales para determinar qué tipo de ejercicio físico se debe prescribir para cada persona, con sus respectivas características tanto del individuo como las del ejercicio.

- Conocimiento del estado actual de las capacidades, indicando este con plena claridad qué tipo de trabajo debe desarrollar para cada componente de la condición física.

- $\quad$ Prescripción del ejercicio físico, determinando las cargas de trabajo adecuadas para cada individuo y que se direccionen al logro de los objetivos y metas propuestos según el diagnóstico inicial, teniendo en cuenta las variaciones que se le indiquen a lo largo del programa.

- $\quad$ Planificación y programación del ejercicio físico, la planeación y programación de los ejercicios deben de estar acordes a las necesidades de cada individuo, teniendo muy presente la prescripción del ejercicio físico para cada persona. Además dentro de la planificación se deben tener en cuenta los principios del entrenamiento tanto los biológicos como los pedagógicos, para no alcanzar un estado inadecuado del usuario y hacer que caiga en un estado de deserción.

- $\quad$ Ejecución y control, a la hora que cada persona desarrolle su programa de ejercicios debe de estar vigilado y tener un control por parte de un profesional en el área de la salud, quien debe conocer plena y profundamente los antecedentes del individuo, sus objetivos y el programa, para lograr un desarrollo óptimo y satisfacer las necesidades y deseos del usuario, además de este control debe realizar evaluaciones periódicas que confirmen la evolución del individuo, verificando su progreso de acuerdo a la planteado en el programa.

Con base a lo anterior, es importante tener presente los elementos tangibles de las instalaciones ya que la calidad del servicio depende de ellos. (Afthinos, Theodorakis, y Nassis, 2005). Surge una hipótesis que hace referencia a 
las principales razones para dejar la membresía en los centros deportivos está relacionado con la insatisfacción de los clientes con lo tangible y las instalaciones deportivas. (Nuviola, 2013)

\subsection{SEGMENTACIÓN DE CENTROS DEPORTIVOS.}

La gestión de un centro deportivo no puede estar supeditada solamente a la experiencia previa o al mero azar; debe aplicar instrumentos que analicen eficientemente el mercado para conocer sus necesidades y actuar en consecuencia, poniendo en marcha estrategias previamente definidas. Así mismo, no podemos obviar que el Centro Deportivo es una empresa que comercializa servicios y que el conocimiento de su naturaleza intangible es clave para la supervivencia del negocio.

La segmentación es una herramienta clave para el posicionamiento y la gestión estratégica de este nuevo tipo de organizaciones que constituyen los centros deportivos. La delimitación de segmentos diferenciales favorece la orientación de la oferta de servicios y la asunción de nuevas inversiones en ámbitos verdaderamente rentables para el futuro organizacional. Asumiendo que existen diferentes grupos de consumidores con necesidades, actitudes, motivaciones y comportamientos particulares, la segmentación permite su identificación y caracterización y, en consecuencia, una mejor comprensión del mercado.

Se han propuesto estrategias y procedimientos muy diversos para intentar segmentar un mercado. En primer término, se han tenido en cuenta criterios sociodemográficos que categorizan a los sujetos en función de su Edad, Sexo u Ocupación. Estos criterios han demostrado tener históricamente una elevada capacidad explicativa, pero han perdido protagonismo en mercados relativamente maduros. Esta perspectiva comienza a dotar a la segmentación deportiva de variables más ajustadas a poblaciones y sectores concretos, introduciendo aspectos que la enriquecen a partir de las características que vinculan al sujeto con el producto o servicio y con la vivencia de consumo. Por su parte, algunos autores conceden una importancia cada vez mayor a variables subjetivas como la personalidad, la percepción, el estilo de vida, la actitud o las preferencias, como referentes válidos y determinantes en la caracterización de colectividades (Boubeta et al., 2009). 


\subsubsection{IMPORTANCIA DE LA SEGMENTACIÓN.}

Existen diferentes tipos de segmentaciones, destacando la sociodemográfica, geográfica, psicográfica, sociocultural o comportamental. El primer tipo, es el más fácil de adquirir y normalmente es el que más se realiza. Su segmentación hace referencia a la categorización de clientes en función de las características demográficas. La geográfica divide al cliente según la ciudad de procedencia, siendo la sociocultural aquella que lo hace según el ciclo de vida familiar o clase social. En relación a la segmentación psicográfica, el mercado queda dividido de acuerdo a diferencias de estilo de vida o criterios de personalidad. Asimismo, concretamente en el sector del fitness, existen estudios que segmentan los usuarios, según la motivación de práctica (Teixeira y Correia, 2009), según una segmentación integral (Rial, Alonso, Rial, Picón y Varela, 2009), según el estilo de vida Suresh, Ravichandran y Ganesan (2011), o según variables motivacionales y sociodemográficas (Afthinos et al., 2005). No obstante, aún quedan otras incógnitas como cuáles son las características dependiendo del país al que pertenezcan.

\subsubsection{USUARIOS (SATISFACCIÓN).}

La Real Academia Española (RAE) define el concepto de usuario con simpleza y precisión: un usuario es quien usa ordinariamente algo. El término, que procede del latín usuarius, hace mención a la persona que utiliza algún tipo de objeto o que es destinataria de un servicio, ya sea privado o público.

El usuario de un gimnasio o CAPF, asiste a este tipo de instituciones en la búsqueda de servicios que llenen sus expectativas y les brinde la posibilidad de cumplir sus objetivos. Se debe tener en cuenta que este usuario se puede clasificar como fijo, el cual es aquel que hace ejercicio periódicamente convirtiéndolo en un hábito positivo de salud y vida, como compromiso con su bienestar biológico, psicológico y social, y que en algunos casos no le es representativo estéticamente sino más bien el incremento de sus niveles de condición física.

El otro tipo de usuario en un gimnasio o CAPF es el usuario ocasional, aquellos que asisten una o dos veces a la semana pero no buscan un objetivo con su asistencia, simplemente se dejan atrapar o seducir por el ritmo de la 
música, por lo atractivo de la locación, por simple curiosidad, por invitación, o el simple deseo de formar parte de círculo social, así sea por un instante, y que por lograr un alto nivel de cumplimiento de sus expectativas termina atrapado y se convierta en un cliente fijo y regular del ejercicio físico. Por lo tanto el perfil del usuario es primordial en el momento en que se le ofrece los servicios y programas.

No se puede dejar de lado los servicios que cada establecimiento ofrece, de estos depende en gran parte que el usuario se quede en el gimnasio o que simplemente no esté de acuerdo y desista de el mismo; los programas que se les esté brindando al usuario pueden estar ligados al mejoramiento de la salud y a la práctica de actividad física.

La valoración de los servicios deportivos es uno de los hechos más estudiados en la actualidad debido a la necesidad de comprender el comportamiento de los usuarios y por el aprovechamiento de la información que las organizaciones obtienen gracias a este tipo de investigaciones. Existen distintos instrumentos de medida pero presentan diversas limitaciones. El objetivo es validar un instrumento y constatar la fiabilidad del mismo como medio de evaluación de los servicios que prestan las diferentes organizaciones deportivas. Para esta investigación se construyó un cuestionario conformado por tres áreas: calidad percibida, satisfacción y valor percibido. Se realizó un análisis estadístico de los ítems, un análisis factorial exploratorio, un análisis factorial confirmatorio y se determinó la validez. Los resultados se materializaron en un cuestionario final compuesto por ocho dimensiones y 25 ítems, capaz de evaluar la calidad percibida, satisfacción y valor percibido del servicio que prestan las organizaciones deportivas (Nuviola, 2013).

En una investigación que se realizó en la ciudad de Almería en la Universidad de Almería, buscaban analizar el perfil del usuario de los centros deportivos enfocándose en el perfil sociodemográfico de los usuarios determinando la composición de grupos de edad y sexo, conocer la situación laboral y económica que rodeaba el usuario; analizar el perfil físico deportivo del usuario previo a la matricula del centro para conocer la demanda deportiva de antes, indagar, describir, analizar y conocer la pertenencia previa a otros centros y la actividad físico deportiva realizada, analizaron el perfil de practica físico deportivo del usuario dentro de este centro y además analizaron el perfil 
motivacional del usuario asociado a la práctica físico deportiva, dando como resultado algunas de las respuestas que ellos buscaban; el medio más eficaz por lo que el usuario conocía la existencia del centro deportivo se debía al boca a boca o tradición oral; los motivos principales que expresan los usuarios para haberse matriculado en alguno de los centros deportivos se debía a la cercanía a su hogar, esto da una muestra que no solo los usuarios asisten a los gimnasios y/o a los centros de acondicionamiento físico por los programas o los servicios que ofertan, sino por los diferentes factores antes mencionados.

El instructor o el acondicionador físico juega un rol importante con este tipo de usuarios sea fijo u ocasional, merecen toda la atención y compromiso por parte de los mismos ya que de ello es que las instituciones funcionan y crecen en el mercado. (Rodríguez, Soto, Camacho y Cantón, 2008).

Hoy en día la asistencia y permanencia en los centros fitness ha venido en aumento por parte de las diferentes poblaciones tanto juveniles como mayores, ya que la salud, la calidad de vida y el aspecto corporal se han visto beneficiados por la práctica de la actividad física.

En la actualidad se ha hecho evidente el aumento considerable de la asistencia de usuarios mayores de 55 años de edad a los centros fitness en España debido al cambio cultural de las personas, trayendo consigo un gran interés dentro de las organizaciones deportivas, lo cual obliga a desarrollar estrategias para mejorar la calidad en el servicio y así poder ofrecer a esta población un amplio y gustoso portafolio de servicios, con el único objetivo de atraer a la población mayor para que desarrollen procesos de actividad física dentro de sus instalaciones.

Esta evolución ha fomentado el interés para que selleven a cabo investigaciones, cuyo objetivo sea identificar y determinar los aspectos a tener en cuenta a la hora de la búsqueda del máximo rendimiento desde la calidad percibida de los servicios, teniendo en cuenta tres factores importantes como los empleados, usuarios y equipamiento.

De otro lado, la calidad y satisfacción de los servicios es de vital importancia para cada uno de los centros deportivos, ya que de esto depende que los usuarios tomen estos centros como sitios especializados y óptimos para la práctica de actividades físicas y deportivas. 
En Sevilla, España se realizó una investigación sobre: Calidad, satisfacción y valor percibido de los usuarios de un servicio deportivo público, donde la muestra fue de 646 usuarios inscritos en actividades del Instituto Municipal de Deportes de Sevilla (IMD), donde cada sujeto llenaba un cuestionario compuesto por 25 ítems. Los resultados obtenidos mostraron que la calidad del servicio recibida fue buena, donde los factores técnicos y personal de servicios fueron los mejores evaluados, las actividades realizadas en las diferentes modalidades que practicaban, también tuvieran una respuesta buena, siendo el Fitness el servicio deportivo más utilizado por los usuarios del IMD de Sevilla. (Nuviala, et al. 2012)

Al hablar sobre características sociodemográficas en cuanto a sexo o edad, los resultados son diferentes y depende únicamente del lugar donde se esté aplicando el estudio. En un estudio realizado en Barcelona por ejemplo, se demostró que "las mujeres están más satisfechas que los hombres en cuanto al servicio recibido en las instalaciones deportivas" (Elasri, Triadó, y Aparicio, 2015, p. 112). Ahora en relación con la edad, se afirma en este mismo estudio que "Existe una correlación positiva -pero no significativa estadísticamenteentre la edad del usuario y su nivel de satisfacción con el centro" (p. 113). Al respecto, los autores de señalan además que la satisfacción es mayor, a más edad, y menor, para quienes están más jóvenes. Finalmente, concluyen en que las dimensiones más importantes que caracterizan dicha satisfacción por parte del cliente, tiene que ver en general: con la calidad de las instalaciones, los recursos humanos, la comunicación, el entorno social y la calidad y precio del centro deportivo. (Elasri et al., 2015).

Por otro lado, hay un gran interés por parte de los campos académicos y profesionales para conocer el funcionamiento de las empresas de deportes desde el punto de vista del usuario y de los espectadores deportivos. Este estudio analiza las relaciones entre la calidad del servicio, valor percibido, satisfacción, futuras intenciones y emociones de una competición de baloncesto profesional.

Los espectadores tienen gran importancia en la sostenibilidad de los equipos deportivos profesionales, ya que dependiendo de la satisfacción que le genere su equipo se realizarán estrategias para la retención y la fidelidad; por lo tanto 
la satisfacción es un punto focal para la gestión deportiva y la investigación ya que esta es una consecuencia de la calidad del servicio. Las relaciones entre la calidad del servicio, la satisfacción, valor percibido, y futuras intenciones son un tema de actualidad en el sector del deporte profesional.

Si se realiza una comparación con la investigación a realizar en este proyecto seguramente se darán cuenta que la fidelidad de un usuario hacia un centro fitness dependen mucho de las variables que éste les ofrezca, brindando a él satisfacción física y mental, también ofreciéndole el valor personal que le dan los programas y servicios del centro y sobre todo las intenciones de cada día por llegar al lugar que tantos beneficios físicos y emocionales le da. El consumo de los eventos; programas y servicios que ofrecen estos centros deportivos son actividades hedonistas ya que están dando al usuario emociones placenteras.

La poca investigación que hay sobre el efecto obvio que tienen las emociones en la gestión diaria de un evento deportivo, hacen que esos clientes y usuarios que estén unidos por emociones fuertes invierten más en sus relaciones que aquellos que carecen de compromiso afectivo es decir; si un partido de baloncesto tiene una cantidad de clientes satisfechos por las sensaciones que le está brindando el equipo, estos tendrán la intención de invertir en eventos próximos.

En resumen, el modelo de investigación pone a prueba los efectos de tres construcciones: la calidad del servicio en la satisfacción y el valor percibido; valor en la satisfacción y futuras intenciones percibidas; y la satisfacción del espectador sobre las futuras intenciones .Por último, el modelo pone a prueba el efecto moderador de las emociones de los espectadores en estas relaciones.

Este estudio explora las relaciones entre la calidad del servicio, la satisfacción, valor percibido, y futuras intenciones bajo el efecto moderador de las emociones. La calidad percibida es un antecedente del valor percibido. Los resultados, que muestran la calidad percibida para ser un antecedente del valor percibido. Varios estudios encuentran que la calidad del servicio y el valor percibido son buenos predictores de la satisfacción .Los resultados indican que la calidad percibida y el valor percibido tienen relaciones positivas y directas con satisfacción. El valor percibido es la variable más influyente. 
El modelo confirma que las intenciones futuras dependen de valor percibido y la satisfacción, con el valor percibido emergiendo como un mejor predicho de la satisfacción. Para satisfacción,). En la identificación de valor percibido como un antecedente del comportamiento futuro, los resultados son consistentes con los de estudios anteriores. Es importante destacar que el valor percibido predice mejor futuras intenciones que la satisfacción.

Respecto al efecto de emociones en la satisfacción y las futuras intenciones. Sorprendentemente, después de espectadores experimentan placer y la excitación con mayor intensidad, la calidad se convierte en un mejor calificador de la satisfacción que el valor percibido. Este cambio se puede producir porque el valor percibido tiene un mayor componente cognitivo que la calidad. Por lo tanto, en los estados de intensa emoción, calidad explica mejor la satisfacción. En general, el campo de la gestión deportiva debe poner mayor énfasis en la investigación sobre el efecto de las experiencias de los espectadores y usuarios de centros deportivos. Este estudio contribuye a este objetivo mediante la observación de los efectos de una de esas variables, las emociones.

\subsubsection{MARKETING (VALOR).}

Conceptualmente, el marketing es considerado como "un planteamiento organizativo que parte de las necesidades, preferencias, deseos así como exigencias de un grupo considerado como objetivo para producir ofertas adecuados a la demanda" (Sandoval, 2015, p. 3). Es decir, el marketing es una preparación que nos permite identificar lo que espera el cliente que le proporcionemos, y desde ese punto, se promociona objetivamente lo que el cliente quiere recibir. Desde esta perspectiva "el producto, propuesto por el marketing, es la oferta de solución concreta diseñada expresamente para satisfacer la necesidad del grupo objetivo" (p. 4).

De otro lado, para muchas personas el concepto de marketing significa promoción, venta directa, correo, Internet. El significado más común procede de los años cincuenta, cuando los fabricantes comenzaron a promover enérgicamente sus productos en todos los medios de comunicación: carteleras, revistas, diarios, radio y televisión. 
Los gimnasios y centros de acondicionamiento físico han crecido tanto en el mercado que se han visto en la necesidad de usar el marketing para la comercialización y prestación de sus servicios; Las necesidades de estos dependen de los objetivos y metas que se quieren lograr para ganar dinero, retener y atraer más usuarios. La percepción que hay en el mercado con respecto a diferenciar un establecimiento de los demás tomando en cuenta la identificación con una marca depende de la estrategia de marketing que utilice la empresa. En términos más simples, se puede afirmar que el marketing orienta los esfuerzos de la organización hacia el objetivo primero de ganar dinero, lograr la fidelidad de su clientela y consumarse como un referente en el mercado. Se puede afirmar que lo que hace tan importante la aplicación de las técnicas del marketing en el sector del fitness, es lograr que el público en general que tenga las posibilidades económicas, físicas y de acceder a un centro $\mathrm{u}$ otro, logren identificar un centro en particular y percibir las características de servicio y productos que se les ofrece del mismo aún sin haberlas probado.

\section{El proceso de Marketing:}

Los cinco pasos del proceso de marketing. En los primeros cuatro pasos, las compañías realizan acciones para entender a los consumidores, crear valor para el cliente y establecer relaciones firmes con esté. En el último paso, las compañías obtienen los beneficios de crear un valor superior en el cliente. Al crear valor para los consumidores, ellas, a la vez, captan el valor de los consumidores en forma de ventas, ingresos y utilidades a largo plazo del cliente. (Kotler y Armstrong, 2003). 
A continuación, se ejemplifica el proceso de marketing en la siguiente figura:

Figura 1. El proceso de Marketing

\section{EL PROCESO DE MARKETING}

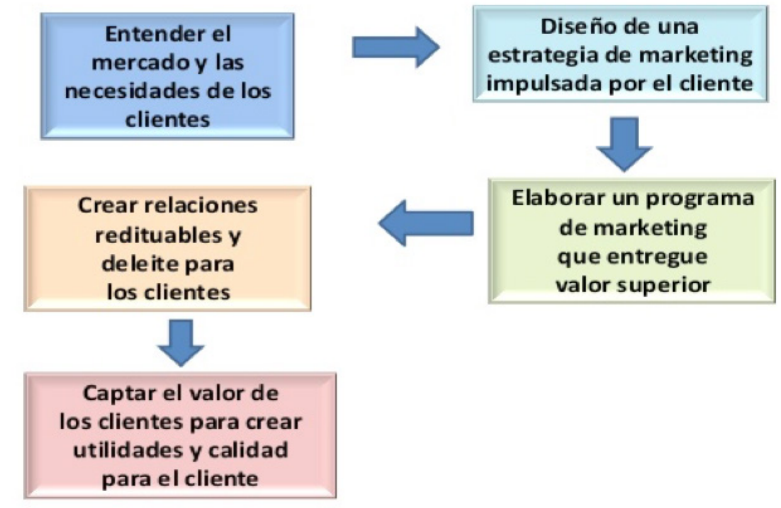

Fuente: Kotler y Armstrong (2003).

Por otra parte, para entender la importancia que tienen aspectos como la satisfacción de los clientes de los gimnasios pero en general de cualquier evento deportivo, adquiere un valor relevante sobre todo si lo que se pretende es la permanencia de los mismos, es por eso que abordaremos el tema intentando conocer todos los elementos que convergen allí.

La satisfacción es un elemento clave en las estrategias de retención y fidelización de los clientes; en los eventos deportivos, se ha encontrado que la satisfacción del espectador es un predictor de antecedente significativo de las intenciones futuras de asistir (Cronin, Brady y Hult, 2002).

Uno de los retos de los gimnasios no solamente es atraer a nuevos usuarios sino también sostener los ya existentes; por lo tanto la importancia de tener un cliente satisfecho. De igual forma, "la satisfacción puede ser definida como la comparación entre las expectativas y la percepción de la calidad del servicio recibido por el usuario" (Shonk y Chelladuri, 2008). 
Ahora bien, "el valor percibido del consumidor es la percepción que hace del conjunto de beneficios obtenidos en el intercambio y el coste incurrido para obtener los beneficios deseados" (Chen y Dubinsky, 2003). Así mismo y no menos importante es que en el valor percibido, están los tangibles; que los definen como: "los ítems relacionados con la apariencia de la instalaciones físicas, equipos, personal y materiales de comunicación” (Calabug, Crespo y Mundina, 2012).

Estos mismos autores en su estudio concluyen que:

los eventos deportivos deben hacer esfuerzos por mejorar la calidad de los tangibles y el valor monetario de sus servicios para aumentar la satisfacción de los espectadores y retenerles para el futuro. En definitiva y a modo de conclusión, el coste percibido pasa a ser un elemento central en la formación de la satisfacción de las intenciones comportamentales de los espectadores de eventos deportivos y en consecuencia se deberán hacer más esfuerzos desde lo profesional, pero sobre todo desde el mundo académico, para intentar diseccionar el constructo de valor coste percibido y comprender mejor los mecanismos de su formación para mejorar, en definitiva, la rentabilidad de los eventos deportivos (Calabug et al., 2012).

En una investigación sobre el análisis de la literatura existente en gestión y marketing de la industria de gimnasio desarrollado en la ciudad de Sevilla España, se describe un análisis de la literatura para proporcionar un amplia visión general del estado actual de la investigación sobre la gestión y comercialización de centros fitness, las fuentes fueron los datos electrónicos y los términos de búsqueda gimnasio industria y gimnasio; las áreas temáticas de los artículos en el orden del mayor número a la menor cantidad de publicaciones fueron : la calidad, la satisfacción y la lealtad, los recursos humanos, aspectos sociológicos, cultura organizacional, segmentación, instalaciones deportivas y de innovación (Fernández, Ruiz, García y Colón, 2016).

Como se puede observar muchos de estos términos que muestra la anterior investigación lo hemos abordado en el presente estudio, ratificando la importancia que tienen dichos conceptos en la industria de los gimnasios. 
Debido a que la industria del fitness es una industria de servicios, se podría sugerir que desempeñan los recursos humanos un papel influyente. Los estudios concluyen que en la mayoría de los casos, los artículos relativos a recursos humanos estipulan estos como el problema más común de preocupación para los investigadores, que puede ser debido a la industria del fitness insistiendo firmemente en el servicio al cliente (García, Fernandez, Durán y Vélez, 2015).

Por otro lado, respecto a la segmentación algunos:

Autores como Woolf (2008) argumentan la necesidad de conocer a los usuarios de los centros de fitness con la idea de ofrecer un servicio adaptado a sus necesidades. Levanta los paquetes de servicios como ventaja competitiva dentro de la industria del fitness y afirma que se pueden aplicar los gimnasios estrategias de marketing mediante el desarrollo de diferentes paquetes con servicios complementarios que son más personalizado y basado en los perfiles de los consumidores (cit en. García et al., 2015).

Las instalaciones deportivas, la innovación y los aspectos sociológicos son en menor medida temáticas que se encuentran en la literatura en gestión y marketing de la industria de gimnasios.

Finalmente es importante mencionar además que el marketing en el sector público se puede aplicar de distintas formas, en especial, en la prestación de servicios públicos: investigación de mercados, diferenciación y segmentación de las ofertas, desarrollo y mejora de servicios y productos, fijación de precios, incentivos y desincentivos económicos, comunicación eficaz con los públicos clave, optimización de canales de distribución, mejoramiento de la satisfacción de los usuarios entre otras (Kotler y Lee, 2011).

\subsubsection{CALIDAD DE LOS COLABORADORES.}

Para poder abordar el término "Talento Humano" iniciaremos con una corta introducción al término "Talento" y a los elementos que lo componen. De acuerdo con Zabala (2008), el talento es un repertorio de capacidades útiles (que posee una persona) para la resolución de problemas, dentro de un espacio de conocimientos, en donde nacen las respuestas acertadas a las distintas situaciones en las que actúa. Por lo tanto, el talento se compone de 
una dimensión innata que se relaciona con las capacidades genéticas de la persona y otra aprendida que se relaciona con las experiencias adquiridas en la interacción con el medio social. La suma de estas dos dimensiones permiten que el talento sea único en cada persona y a su vez, promueve el desarrollo de aptitudes y destrezas singulares que le posibilitan al individuo sobresalir en un determinado entorno frente a la solución de una tarea en forma exitosa.

Dado lo anterior, el Talento Humano podemos entenderlo como la capacidad y destreza que tiene una persona para resolver un problema o enfrentarse a una situación de manera exitosa, haciendo uso de todas sus potencialidades. Por lo tanto, no se restringe sólo a las habilidades cognitivas de una persona o a los estudios que haya realizado, sino a la capacidad de combinar todo este bagaje cognitivo con las experiencias previas y futuras, la capacidad de adaptación, la resolución de problemas, la pro actividad, el trabajo en equipo y demás habilidades psicológicas, cognitivas y sociales en pro del desarrollo de los ideales y metas de una organización.

En consecuencia, el Talento Humano se convierte en el principal recurso con el que cuenta una organización o empresa pues las ideas y conocimientos que aportan las personas que las conforman para responder a unas metas y filosofías institucionales, le permite a ésta ser competitiva e innovadora.

Para el caso de los CAPF, el talento humano necesario para su óptimo funcionamiento debe estar compuesto por un grupo de profesionales de diferentes disciplinas que aporten conocimientos específicos de actividad física, morfología, fisiología, entrenamiento deportivo, psicología y primeros auxilios trabajando interdisciplinariamente en pro del beneficio de los diferentes usuarios. Toro y Pereira (2013) mencionan que se requiere que en estos centros se cuente con personas profesionales en gerencia, administración, acondicionamiento físico e instructores de actividad física.

En el presente estudio se evaluará la conformidad de los usuarios con el servicio, programas y talento humano de algunos gimnasios de la ciudad de Pereira (Colombia), se verá grandemente influenciada por el nivel académico, experiencia y carácter de las personas encargadas de la atención al cliente. Todos los empleados son importantes y determinantes en la imagen, atención y servicio que se preste. 
Por consiguiente la experiencia de los participantes de deportes activos o recreativos tiende a ser influenciados por la localización del entorno físico, instalaciones limpias y cuidadas, buenos equipos y la calidad de la relación con los instructores o funcionarios. Los usuarios manifiestan que para ellos es más importante la calidad de las instalaciones especialmente el aseo y el contacto con el personal que hace la atención, que los servicios básicos y auxiliares. Sin embargo, en necesario tener en cuenta que las personas que participaron en el estudio se clasificaron en dos grupos, los que van de forma recreativa o como iniciación que requieren instructor y los deportistas que ya tienen su rutina establecida y básicamente tienen contacto solo con la recepcionista. No obstante, se observó que para ambos grupos era importante percibir la idoneidad de cada empleado en su labor.

Finalmente, el estudio permite establecer que la lealtad, permanencia y adherencia de las personas que asisten a los centros acuáticos, depende fundamentalmente de la relación que se establece con los empleados. Por lo tanto, reconoce la importancia del recurso humano capacitado, no sólo para la atención profesional de las modalidades y servicios ofrecidos por el centro sino en la calidad humana de cada uno de sus empleados, desde la recepcionista hasta el personal operativo.

\subsection{REFERENTE CONTEXTUAL}

\subsubsection{CASO COLOMBIANO “CENTROS FITNESS EN PEREIRA”.}

Registro. Es la recolección y sistematización de los datos suministrados por los gimnasios, para que sean reconocidos ante los organismos correspondientes de autorización, siendo este el único requisito para ser sujetos de inspección y control como establecimientos comerciales, al igual que queden registrados los servicios, los beneficiarios y el talento humano ante el mecanismo de Registro Único Nacional (RUN), implementado por el Sistema Nacional del Deporte.

Categorización. Es la clasificación que se le dará a cada establecimiento constituido como gimnasio, de acuerdo a la información recolectada en el Registro sobre el talento humano, los servicios, los recursos físicos y los beneficiarios con los que cuenta el establecimiento, logrando así determinar los servicios que pueden ofrecer y las personas que pueden ser atendidas. 
Autorización. Es el aval de funcionamiento que debe otorgar a los gimnasios de todos los niveles la Secretaria de Deporte y Recreación del municipio, conforme a lo estipulado por el Artículo 81 de la Ley 181 de 1995.

Habilitación. Es el cumplimiento de requisitos mínimos de garantía en la prestación de servicios relacionados con salud. Ésta se implementa únicamente en los Centros de acondicionamiento y preparación física con Supervisión Especializada (nivel 3), teniendo en cuenta que éstos deben tener unas características específicas en cuanto a talento humano y recursos físicos por el tipo de servicios prestados y la clase de usuarios. Dicha habilitación se realizará por medio de la Secretaria de Salud Municipal.

Tipos de usuario. El Colegio Americano de Medicina del Deporte14 hace una clasificación de los usuarios de acuerdo a sus factores de riesgos:

- Usuarios Clase A-1. Usuarios aparentemente sanos; esta clase incluye niños, adolescentes y adultos (Hombres $<45$ años y Mujeres $<55$ años). Personas sin ningún factor de riesgo cardiovascular y sin enfermedad cardiovascular (ECV) comprobada.

- Usuarios Clase A-2. Usuarios aparentemente sanos; incluye adultos (Hombres > 45 años y Mujeres > 55 años). Personas sin ningún factor de riesgo cardiovascular y sin ECV comprobada.

- Usuarios Clase A-3. Usuarios aparentemente sanos; esta clase incluye adultos (Hombres > 45 años y Mujeres > 55 años). Personas con 2 o más factores de riesgo cardiovascular y sin ECV comprobada.

- Usuarios Clase B. Usuarios con ECV conocida (controlada); esta clase incluye niños, adolescentes, hombres y mujeres que pueden tener o no algún factor de riesgo cardiovascular.

- Usuarios Clase C. Personas con riesgo moderado a alto de complicaciones cardiacas durante el ejercicio y/o que no son capaces de autorregular la actividad o comprender el nivel recomendado de actividad. 
Centros Fitness. Son establecimientos que prestan diferentes servicios de actividad física, teniendo en cuenta una dieta saludable, una vida sana y el ejercicio físico desde una visión de salud. Con el objetivo favorecer la salud y la calidad de vida del usuario.

Para efectos del presente proyecto será empleada la siguiente clasificación:

- $\quad$ Centro Fitness con Supervisión Básica. Establecimientos que ofrecen servicios básicos de actividad física, empleando recursos físicos básicos. Dichos establecimientos cuentan con Instructor Fitness (ver definición en el siguiente aparte).

- Centros Fitness con Supervisión Profesional. Establecimientos aptos para atender usuarios hasta clase B. Estos establecimientos cuentan con Instructores Fitness, los cuales estarán bajo la supervisión de un Profesional en el área de la actividad física y/o el deporte, quien se denominará Coordinador Fitness (ver definición en el siguiente aparte).

- Centros Fitness con Supervisión Específica. Estos establecimientos podrán desarrollar servicios para usuarios hasta clase C. Los programas deberán ser ejecutados a través de un proceso interdisciplinario entre profesionales en áreas afines a la actividad física, el deporte, la salud y la estética.

Instructor Fitness. Persona con competencias básicas en actividad física y/o deporte. Apta para direccionar los procesos de usuarios hasta clase A2.

Coordinador Fitness. Persona con competencias profesionales en actividad física y/o deporte. Podrán desarrollar programas para usuarios hasta clase B.

Profesional de la salud. Persona con competencias específicas en medicina, fisioterapia, kinesiología, nutrición u otras áreas relacionadas con la salud y la estética corporal, idónea para el desarrollo de servicios de manera segura y efectiva para usuarios de todas las clases. 


\subsubsection{CARACTERÍSTICAS GENERALES DE LOS GIMNASIOS DE PEREIRA.}

\subsubsection{GIMNASIO SPINNING CENTER GYM PEREIRA.}

Acogiéndose a las leyes colombianas en el mes de octubre del año 1998 bajo la iniciativa de un grupo de amigos de crear un centro médico deportivo especializado en Indoor Cycling, nació en Bogotá el Spinning Center Gym, siendo el primero en la ciudad y el país, en ofrecer clases diferenciadas, de acuerdo al nivel del usuario y sus objetivos. Debido al gran éxito del proyecto, decidieron ampliar el portafolio de servicios y se convirtió así en una cadena de gimnasios, que actualmente cuenta con siete sedes en Bogotá, una en Ibagué y una en la ciudad de Pereira, posicionándose como uno de los mejores gimnasios en el país.

La misión del gimnasio es aportar bienestar y salud a la población colombiana, por medio de los servicios médicos deportivos cumpliendo con altos estándares de calidad en infraestructura, tecnología y recurso humano, ofreciendo el mejor costo- beneficio del mercado.

La visión es ser el líder a nivel nacional en prestación de servicios de nutrición, prevención, y actividad física, utilizando todos los recursos disponibles en la industria fitness.

En la ciudad de Pereira comienza su funcionamiento en los primeros meses del año 2015, está ubicado en el quinto nivel del Centro Comercial Arboleda, ubicado en la avenida Circunvalar $N^{\circ} 5-20$, inicia su funcionamiento ofreciendo servicios atractivos para captar la mayor población posible con un portafolio de servicios que consta de una zona de ejercicio cardiovascular, una sala de spinning, un salón múltiple de aeróbicos, la zona de trabajo de fuerza que está conformada por máquinas de polea, los hammer, la zona de mancuernas y barras, la zona de entrenamiento funcional, el turco, también para el mejor desempeño y aprovechamiento del ejercicio. Tiene colaboradores como; un médico deportólogo, una fisioterapeuta, una nutricionista, dos entrenadores personales, tres entrenadores de planta, seis entrenadores de clases grupales. Las instalaciones en el centro comercial, permiten a los 
afiliados gozar de beneficios como parqueadero gratuito y vigilado, una amplia y extensa red de establecimientos comerciales, una amplio hall de comidas, la red bancaria, salas de cine, parque de juegos infantiles; todo esto le agrega un incentivo más para afiliarse al Spinning Center, además de un horario flexible que permite que en cualquier día de la semana se pueda ir a realizar la rutina de ejercicios cardiovascular o de fuerza, trabajando de 05:00a.m., a 10:00p.m. de lunes a jueves, de 05:00a.m a 09:00p.m. los viernes, los sábados de 07:00a.m. a 08:00p.m. y los domingos y festivos de 07:00a.m. a 06:00p.m., en todo momento con la presencia de los entrenadores de planta y algunas clases grupales, además dentro de la estrategia comercial, éste ofrece a los visitantes un recorrido por el gimnasio para conocer las instalaciones completas, dando una clara explicación del tipo de máquinas y poleas que el gimnasio posee, dando a conocer el personal profesional con que se cuenta, $y$ un free pass (pase libre) por tres días, continuos, para que la persona, realice su entrenamiento estos días y conozca y se familiarice con las maquinarias y equipos con que cuenta el gimnasio.

Todas estas estrategias están encaminadas a que el usuario mejore su capacidad física en resistencia, fuerza, movilidad, su autoestima, el cambio de figura y los diferentes estados de salud (Spinning Center Company, 2015).

Figura 2. Zona de Máquinas Gimnasio Spinning Center Gym Pereira

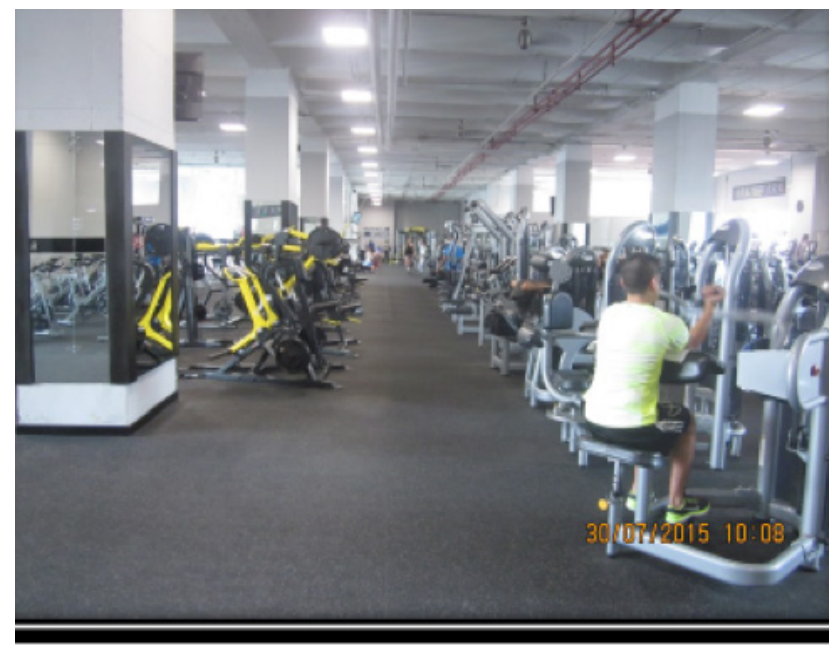

Fuente: tomada por los investigadores 


\subsubsection{GIMNASIO SPORT GYM PEREIRA.}

El gimnasio Sport Gym se encuentra ubicado en la Cra. 2273 A-11 Barrio Cuba, inicio sus labores a comienzos del año 2000, bajo la idea de quien actualmente es su propietario el señor Wilmar Fernando Carrillo, un apasionado por la actividad física.

Para iniciar solo se tenía un salón en el cual se realizaban actividades que involucraran el mismo peso de cada usuario, pocos meses de haber dado apertura las primeras máquinas que obtuvo el gimnasio fueron 2 bicicletas de spinning y una máquina de poleas, así fue creciendo este gimnasio. En la actualidad el gimnasio cuenta con varias zonas como, zona cardiovascular, zona de musculación y zona de clases grupales y artes marciales.

Hoy el gimnasio se ha convertido en un patrimonio familiar, ya que el señor Wilmar Carrillo y su hijo Junior Carrillo son los encargados de administrarlo; el gimnasio funciona de lunes a viernes de 6 am a 10 pm y los sábados de 6 am a $12 \mathrm{~m}$.

Misión: Ayudar a nuestros usuarios a alcanzar sus metas actividad física funcional para el ABC diario, prestando un excelente servicio y calidad humana.

Visión: Ser en el 2018 el mejor centro de acondicionamiento físico y deportivo del barrio Cuba, obteniendo reconocimiento por nuestro excelente servicio de calidad humana hacia el mejoramiento de la calidad de vida de nuestros clientes.

\subsubsection{GIMNASIO ATENAS GYM FITNESS.}

El gimnasio Atenas Gym Fitness se encuentra en Pereira, ubicado en el sector de la ciudadela Cuba, en la comuna el Oso al Occidente de la ciudad, en el barrio La Habana. 
El gimnasio lleva en servicio 3,5 años en las canchas sintéticas del Bernabéu, con horario de funcionamiento de lunes a viernes de 06:00 am a 10:00 pm y los sábados de 06:00 am a 01:00 pm.

Figura 3. Gimnasio Atenas Gym Fitness

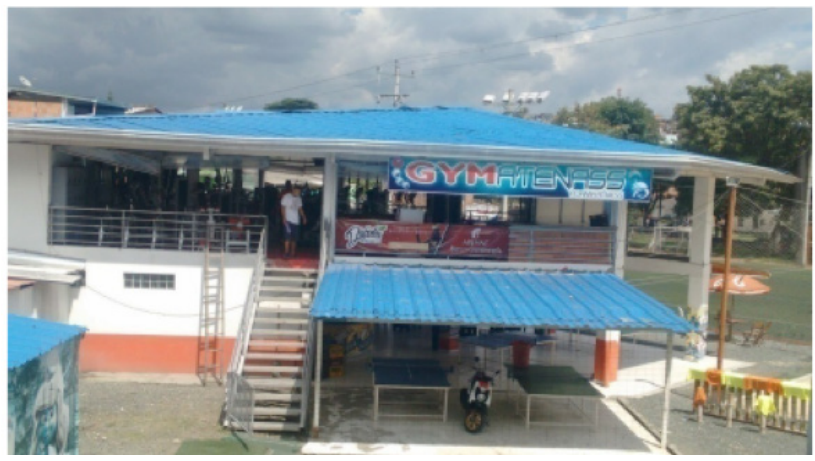

Fuente: tomada por los investigadores

\subsubsection{GIMNASIO SPORT LIFE GYM.}

Sport Life Gym es una empresa dedicada al acondicionamiento físico desde el año 1998. Esta empresa siempre ha estado dedicada a prestar excelentes servicios, ya que su infraestructura, la alta tecnología en equipos y la excelencia en el servicio al cliente; desarrollado en este gimnasio marcan la diferencia en calidad con respecto a otras opciones.

Misión: Ayudar a nuestros usuarios a alcanzar sus metas de actividad física con motivación, energía y calor humano, prestando un excelente servicio y asesoría, para así, gracias a nuestro personal capacitado e infraestructura, llegar a ser la institución deportiva preferida por todos los pereiranos.

Visión: Ser el mejor centro de acondicionamiento físico y deportivo de la ciudad, obteniendo reconocimiento por nuestro excelente servicio, y así, en el año 2017 expandir nuestras instalaciones hacia los municipios más importantes de Risaralda. 


\section{Servicios de actividad física}

- Pesas

- Aeróbicos

- Rumba y Baile

- Yoga

- Step

- Tae-bo

- Baño turco

- Cámara de Bronceo

\section{Otros Servicios}

- Cafetería

- Venta de Ropa deportiva

- Venta de Vitaminas y proteínas

- Asesoría Nutricional

\section{Horarios}

Lunes a viernes: 5:30 a.m. a 9:30 p.m.

Sábados: 8:00 a.m. a 3:00 p.m.

Domingos y festivos: 8:00 a.m. a 12:00 m.

Figura 4. Logo del Gimnasio Sport Life Gym

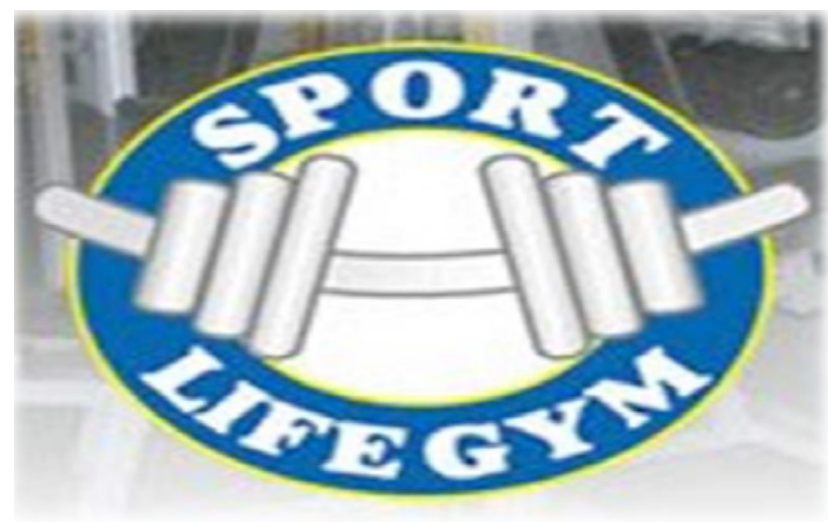

Fuente: tomada por los investigadores 


\subsubsection{GIMNASIO PLATINIUM FITNESS.}

Platinium Fitness, es un Centro de Acondicionamiento Físico, que ofrece servicios de actividad física y deporte enfocados al bienestar y la salud de todos sus usuarios, brindando asesoría muy personalizada y utilizando las más avanzadas técnicas del entrenamiento físico.

El Equipo Platinium, está conformado por un grupo de profesionales en ciencias aplicadas al deporte, la medicina y la estética, unidos para brindar el mejor servicio en entrenamiento físico y mantenimiento de la salud.

\section{Servicios Platinium:}

- Entrenamiento cardiovascular: Se cuenta con modernas máquinas para el entrenamiento aeróbico que permiten llevar el control cardiaco y calórico durante la actividad (caminadoras, elípticas, bicicletas de spin bike).

- Entrenamiento muscular: Maquinaria moderna y acorde para el trabajo de cada grupo muscular del cuerpo, ergonómicamente ajustables a la medida de cada persona, para cuidar al mismo tiempo de la postura y la técnica en pro de la salud.

- $\quad$ Entrenamiento para población especial: Programas diseñados por profesionales para poblaciones con características exclusivas (hipertensos, diabéticos, madres gestantes, adolescentes, discapacidades motrices entre otros).

Contamos con las más modernas camillas de la región para la práctica de este tipo entrenamiento.

\section{Programas Platinium:}

- $\quad$ Reducción de peso

- $\quad$ Aumento de masa muscular

- Tonificación y definición muscular

- Rehabilitación y fortalecimiento

- Mejoramiento de la condición física

- $\quad$ Entrenamiento para madres gestantes 
- $\quad$ Actividad física para la tercera edad

- $\quad$ Ejercicio en trastornos metabólicos (diabetes, hipertensión, etc.)

- $\quad$ Programas especiales para adolescentes

- $\quad$ Evaluación cine antropométrica para todos los usuarios.

Platinium Fitness, es una nueva propuesta en centros de acondicionamiento en la ciudad, cuenta con equipos totalmente nuevos y de la mejor calidad, además ofrece servicio de cafetería, venta de ropa deportiva y otros adicionales para facilitarles la vida a todos los usuarios.

Ubicación: Platinium Fitness, está ubicado en el corazón de la ciudad de Pereira, lo que permite un acceso fácil a nuestras instalaciones en el Centro Comercial Lago plaza, Calle 23 No 8-47, en el piso cuatro (servicio de ascensor).

\section{Horario:}

Lunes a viernes: De 6 a.m. a 9:30 p.m.

Sábados: De 8 a.m. a 3 p.m.

\subsubsection{Gimnasio Ares Gym Pereira}

Quiénes Son: A raíz de la necesidad que tiene el ser humano de conservar su salud y gozar de bienestar surgió la idea de crear una empresa dedicada a satisfacer dicha necesidad, a través de actividades físicas enfocadas al entrenamiento cardiovascular o trabajos de fuerza y/ o anaeróbicos, dependiendo de las diferencias básicas de los biotipos de los usuarios, la trayectoria que tiene el gimnasio data de septiembre del año 2011, y cuenta con personal calificado para la atención integral de los usuarios, ya que son personas con formación deportiva tanto práctica como académica en las disciplinas que se brindan en nuestras instalaciones.

Ares Gym considerando las diferencias de la morfo fisiología humana y de los gustos del usuario y siendo conscientes que un proceso de entrenamiento debe ser individualizado, ha puesto a su servicio personal calificado, que genera fichas de seguimiento las cuales permiten evaluar desde el ingreso el estado físico para realizar el proceso de seguimiento de forma continuada y determinar las rutinas de entrenamiento adecuadas y lograr cambios significativos a nivel de salud, mantenimiento físico y rendimiento cardiovascular. 
Ares Gym se encuentra Dotado con una amplia gama de equipos de alta tecnología:

- $\quad$ Elíptica. Equipo que refleja la combinación entre una escaladora y una máquina de esquiar.

- Bicicletas Estáticas y de Spinning. Ideales para la mayoría de personas, particularmente para aquellas que por diferentes razones necesitan un tipo de ejercicio que soporte el peso corporal (bajo impacto).

- Máquinas Multitarea y peso libre: pesas, discos y mancuernas. Más relacionadas con movimientos ejecutados contra resistencia o de fuerza muscular.

Misión: Ares Gym, basado en la necesidad de los usuarios de propender por su salud, bienestar, y esparcimiento, ha asumido el compromiso de ayudar a alcanzar los objetivos individuales y en mejorar su calidad de vida, brindándole un esmerado servicio, personal altamente capacitado, y con una infraestructura a la vanguardia de la exigencia tecnológica y cultural

Visión: Ares Gym tiene dentro de su plan de crecimiento y expansión constituirse para el 2020 en Pereira la cadena de gimnasios líder en servicios innovadores siempre con el fin de brindar bienestar a los usuarios y en general a la población, generando valor agregado.

\section{Servicios de actividad física}

- Artes Marciales Mixtas

- KickBoxing

- Boxeo

- Pesas

- Karate para niños

- Step

- Spinning

- Aeróbicos

- Rumba terapia 


\section{Otros servicios}

- Venta de Ropa y accesorios deportivos

- Venta de Vitaminas y proteínas

- Asesoría Nutricional

- Evaluación antropométrica

Figura 5. Logo e Instalaciones Gimnasio Ares Gym Pereira
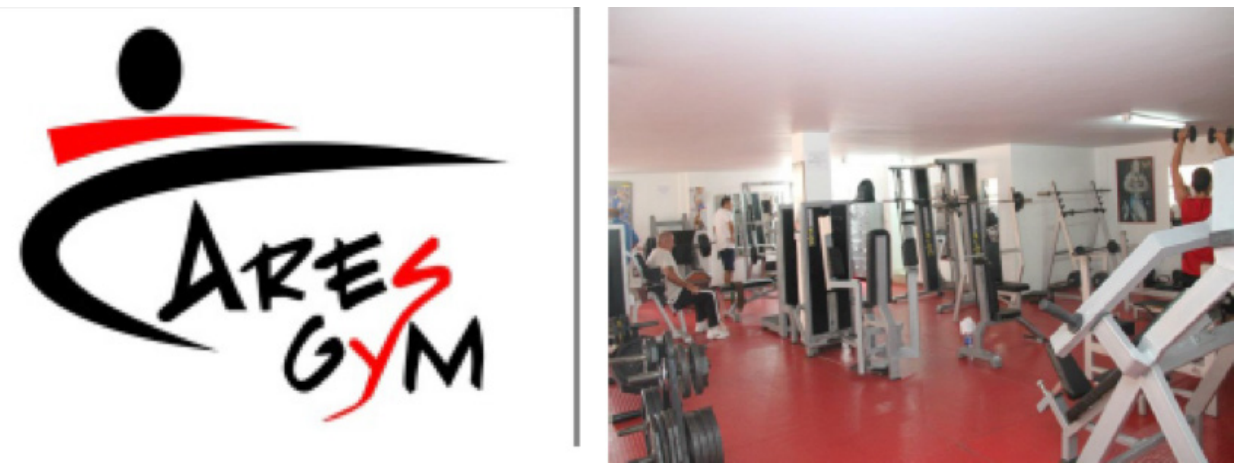

Fuente: tomada por los investigadores

\subsubsection{GIMNASIO SKANDINAVIA}

Misión: Somos el centro de acondicionamiento físico cuya misión es promocionar y mejorar la calidad de vida de nuestros afiliados a través de mejoramiento continuo y evolutivo de sus condiciones físicas, corporales y mentales, mediante programas actividad física sistemática preventiva $\mathrm{y}$ constantemente logre resultados exitosos en tiempo real, nuestro personal está en constante formación y capacitación profesional enfocados en la actividad física funcional para atender a cada usuario de una manera óptima, acorde a las necesidades y evaluaciones individuales establecidas.

Visión: Nuestra proyección está orientada al posicionamiento, como el sitio fitness pionero y líder en sistemas de acondicionamiento físico funcionales hacia la salud, enfocados al bienestar de los usuarios, con instalaciones de vanguardia y servicios complementarios orientados al sistema wellnes(estado de bienestar, definido de acuerdo a las necesidades de cada persona), con ese 
fin brindar profesionales de gran perfil y calidez humana, generando espacios con atmosferas adecuadas para la correcta realización de ejercicios y técnicas físicas evolucionando de forma satisfactoria para todos.

Figura 6. Entrada del gimnasio Skandinavia

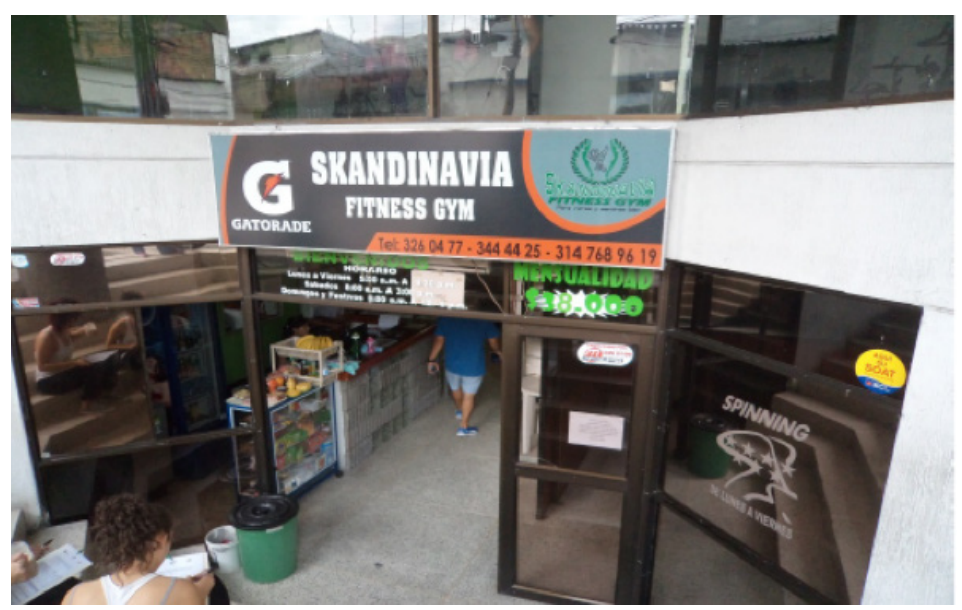


CAPÍTULO II 


\section{CAPÍTULO II. METODOLOGÍA Y RESULTADOS DE LA INVESTIGACIÓN}

\subsection{METODOLOGÍA}

\subsubsection{TIPO Y DISEÑO.}

\subsubsection{TIPO DE INVESTIGACIÓN.}

La presente investigación se desarrolló bajo el paradigma Empírico-analítico y es de tipo descriptiva

\subsubsection{DISEÑO.}

La presente es una investigación descriptiva, porque se identificará el perfil del cliente de los gimnasios y centros de acondicionamiento físico: segmentación por características sociodemográficas y diferencias entre clientes de los gimnasios: Gimnasio Spinning Center Gym, Sport Gym, Atenas Gym Fitness (Barrio Cuba), Sport Life Gym, Platinium Fitness, Ares Gym y Gimnasio Skandinavia de la ciudad de Pereira.

\subsubsection{POBLACIÓN.}

Se trabajó con los usuarios de los diferentes gimnasios de Pereira. Se trabajó con un total de 2100 personas que asisten a los gimnasios a realizar actividad física. 


\title{
2.1.3 VARIABLES DE INVESTIGACIÓN.
}

\author{
Cuadro 1. Variables de investigación
}

\begin{tabular}{|c|c|c|c|}
\hline VARIABLE & DIMENSIÒN & ÍTEM & $\begin{array}{l}\text { OPCIÓN DE } \\
\text { RESPUESTA }\end{array}$ \\
\hline \multirow{3}{*}{$\begin{array}{l}\text { CALIDAD: herramienta } \\
\text { básica e importante para } \\
\text { una propiedad inherente de } \\
\text { cualquier cosa que permite } \\
\text { que la misma sea } \\
\text { comparada con cualquier } \\
\text { otra de su misma especie. }\end{array}$} & $\begin{array}{l}\text { INSTALACIONES: } \\
\text { Conglomerado de } \\
\text { infraestructura, } \\
\text { materiales y elementos } \\
\text { físicos disponibles para } \\
\text { la utilización por parte } \\
\text { de los usuarios. }\end{array}$ & $\begin{array}{l}\text {-Las instalaciones del centro } \\
\text { deportivo son atractivas. } \\
\text {-Las instalaciones del centro } \\
\text { deportivo son espaciosas. } \\
\text {-El ambiente del centro } \\
\text { deportivo (temperatura, } \\
\text { iluminación, ruido y olor) es } \\
\text { bueno. } \\
\text {-El equipamiento del centro } \\
\text { deportivo está en buenas } \\
\text { condiciones. }\end{array}$ & $\begin{array}{l}1=\text { Totalmente en } \\
\text { desacuerdo } \\
9=\text { Totalmente de } \\
\text { acuerdo } \\
123456789\end{array}$ \\
\hline & $\begin{array}{l}\text { EMPLEADOS: } \\
\text { Personal del cual } \\
\text { dispone el centro para } \\
\text { prestarle el servicio al } \\
\text { cliente, requerido por el } \\
\text { usuario. }\end{array}$ & $\begin{array}{l}\text {-Los empleados responden } \\
\text { rápidamente a las necesidades } \\
\text { de los clientes. } \\
\text {-Los empleados trabajan con } \\
\text { entusiasmo. } \\
\text {-Los empleados son educados. } \\
\text {-Los empleados ayudan a que } \\
\text { los clientes se sientan cómodos. } \\
\text {-Los empleados son expertos. }\end{array}$ & $\begin{array}{l}1=\text { Totalmente en } \\
\text { desacuerdo } \\
9=\text { Totalmente de } \\
\text { acuerdo } \\
123456789\end{array}$ \\
\hline & PROGRAMAS & $\begin{array}{l}\text {-Los programas de actividad } \\
\text { fisica me ayudan a incrementar } \\
\text { mi energía. } \\
\text {-Los programas de actividad } \\
\text { fisica me ayudan a mejorar mi } \\
\text { salud. } \\
\text {-Los programas de actividad } \\
\text { física me ayudan a mejorar mi } \\
\text { humor. } \\
\text {-Los programas de actividad } \\
\text { fisica me ayudan a mejorar mi } \\
\text { bienestar psicológico. } \\
\text {-Los programas de actividad } \\
\text { fisica me ayudan a mejorar mi } \\
\text { nivel de condición física. }\end{array}$ & $\begin{array}{l}1=\text { Totalmente en } \\
\text { desacuerdo } \\
9=\text { Totalmente de } \\
\text { acuerdo } \\
123456789\end{array}$ \\
\hline
\end{tabular}




\begin{tabular}{|c|c|c|}
\hline $\begin{array}{l}\text { CALIDAD GENERAL: } \\
\text { propiedad o al conjunto de } \\
\text { ellas que están presentes en } \\
\text { las personas o en las cosas } \\
\text { y que son las que en } \\
\text { definitivas cuentas nos } \\
\text { permitirán apreciarlas y } \\
\text { compararlas con respecto a } \\
\text { las restantes que también } \\
\text { pertenecen a su misma } \\
\text { especie o condición. }\end{array}$ & $\begin{array}{l}\text {-El nivel de los programas y de } \\
\text { los servicios de este centro } \\
\text { deportivo es excelente. } \\
\text {-El nivel de los programas y de } \\
\text { los servicios de este centro } \\
\text { deportivo es muy alto. } \\
\text {-Los programas y los servicios } \\
\text { de este centro deportivo son de } \\
\text { alto nivel. }\end{array}$ & $\begin{array}{l}1=\text { Totalmente en } \\
\text { desacuerdo } \\
\text { 9= Totalmente de } \\
\text { acuerdo } \\
123456789\end{array}$ \\
\hline $\begin{array}{l}\text { VALOR: Cualidad o } \\
\text { conjunto de cualidades por } \\
\text { las que una persona o cosa } \\
\text { es apreciada o bien } \\
\text { considerada. }\end{array}$ & $\begin{array}{l}\text {-Los programas y servicios de } \\
\text { este centro deportivo tienen un } \\
\text { gran valor. } \\
\text {-Los programas y servicios de } \\
\text { este centro deportivo merecen lo } \\
\text { que cuestan. } \\
\text {-Lo que consigo de este centro } \\
\text { deportivo y lo que cuesta, me } \\
\text { ofrece el valor. } \\
\text {-En general, el valor de los } \\
\text { programas y servicios en este } \\
\text { centro deportivo es alto. }\end{array}$ & $\begin{array}{l}\begin{array}{l}1=\text { Totalmente en } \\
\text { desacuerdo }\end{array} \\
9=\text { Totalmente de } \\
\text { acuerdo } \\
123456789\end{array}$ \\
\hline $\begin{array}{l}\text { SATISFACCIÓN: } \\
\text { Sentimiento de bienestar o } \\
\text { placer que se tiene cuando } \\
\text { se ha colmado un deseo o } \\
\text { cubierto una necesidad. }\end{array}$ & $\begin{array}{l}\text {-Estoy satisfecho con los } \\
\text { programas y servicios de este } \\
\text { centro deportivo. } \\
\text {-Soy feliz con los programas y } \\
\text { servicios de este centro } \\
\text { deportivo. } \\
\text {-Estoy satisfecho de haber } \\
\text { tomado la decisión de ser socio } \\
\text { de este centro deportivo. } \\
\text {-Mi decisión de ser socio de este } \\
\text { centro deportivo fue acertada. }\end{array}$ & $\begin{array}{c}\begin{array}{c}1=\text { Totalmente en } \\
\text { desacuerdo }\end{array} \\
9=\text { Totalmente de } \\
\text { acuerdo } \\
123456789\end{array}$ \\
\hline
\end{tabular}




\begin{tabular}{|c|c|c|c|}
\hline $\begin{array}{l}\text { INTENCIONES DE } \\
\text { COMPORTAMIENTO: } \\
\text { Manera de funcionar una } \\
\text { cosa en una situación } \\
\text { determinada. }\end{array}$ & & $\begin{array}{l}\text {-Realizaré comentarios positivos } \\
\text { a un amigo acerca de los } \\
\text { programas y servicios de este } \\
\text { centro deportivo. } \\
\text {-Si me preguntan, recomendaré } \\
\text { este centro deportivo. } \\
\text {-Continuaré participando en los } \\
\text { programas de este centro } \\
\text { deportivo. } \\
\text {-Me volvería a inscribir en este } \\
\text { centro deportivo si me diera de } \\
\text { baja. }\end{array}$ & $\begin{array}{c}\begin{array}{c}1=\text { Totalmente en } \\
\text { desacuerdo }\end{array} \\
9=\begin{array}{c}\text { Totalmente de } \\
\text { acuerdo }\end{array} \\
123456789\end{array}$ \\
\hline \multirow[t]{2}{*}{$\begin{array}{l}\text { PERFIL } \\
\text { SOCIODEMOGRÁFICO } \\
\text { Hace referencia a las } \\
\text { características que se } \\
\text { encuentran en la población } \\
\text { encuestada. }\end{array}$} & $\begin{array}{l}\text { INFORMACIÓN } \\
\text { GENERAL }\end{array}$ & $\begin{array}{l}1 \text { Género } \\
2 \text { Edad } \\
3 \text { Formación académica } \\
4 \text { Ocupación } \\
4 \quad \text { Estado civil } \\
5 \quad \text { Rango salarial }\end{array}$ & $\begin{array}{l}1 \text { Hombre, mujer } \\
2 \text { Años } \\
3 \text { Primaria, } \\
\text { Secundaria, } \\
\text { Universitaria, } \\
\text { Especialización, } \\
\text { Maestría, } \\
\text { Doctorado } \\
4 \text { Estudiante, } \\
\text { Funcionario, } \\
\text { Empleado, } \\
\text { Empresa privada, } \\
\text { Independiente, } \\
\text { Desempleado, } \\
\text { Otro } \\
5 \text { Casado, Soltero, } \\
\text { Otro } \\
61 \text { Salario } \\
\text { mínimo, 1-3 } \\
\text { salarios mínimos, } \\
4-5 \text { salarios } \\
\text { mínimos, más de } 6 \\
\text { salarios mínimos. }\end{array}$ \\
\hline & $\begin{array}{l}\text { UTILIZACIÓN: } \\
\text { Frecuencia con la que } \\
\text { hace uso de los } \\
\text { servicios. }\end{array}$ & $\begin{array}{l}6 \\
\begin{array}{l}\text { Tiempo como usuario del } \\
\text { centro deportivo. }\end{array} \\
7 \text { Cuantos días realiza } \\
\text { actividad física por semana. } \\
8 \text { Tiempo de duración de cada } \\
\text { sesión de actividad física. } \\
9 \text { Actividades que realiza } \\
\text { cuando asiste al centro } \\
\text { deportivo. }\end{array}$ & $\begin{array}{l}7 \text { Años, Meses } \\
8 \text { Semanas } \\
9 \text { Horas } \\
10 \text { Actividades } \\
\text { grupales ( } \\
\text { aeróbicos, yoga, } \\
\text { Pilates, etc.); } \\
\text { Fitness, otras. }\end{array}$ \\
\hline
\end{tabular}

Fuente: elaboración propia 


\subsubsection{TÉCNICAS E INSTRUMENTOS.}

La técnica implementada fue la entrevista, realizada mediante un instrumento dividido en 2 partes, la primera orientada a datos generales o perfil socio demográfico y la segunda con 31 preguntas cerradas sobre calidad (Ver anexo 1 Instrumento).

Este cuestionario se retomó del estudio Perfil del usuario en centros fitness de Sevilla España. Su diseñó se realizó de la siguiente manera: se elaboró el cuestionario dividido en características sociodemográficas del usuario (Género, edad, formación académica, estado civil, permanencia en la instalación y duración de la sesión), así como una encuesta tipo likert con 9 opciones de respuesta $(1=$ totalmente en desacuerdo y $9=$ totalmente de acuerdo). Dicho instrumento estuvo constituido con 15 ítems para la calidad percibida de servicio elaborada a partir de la escala propuesta por Brady y Cronin (2001), y por último una medida para la fidelidad o intenciones de comportamiento de 4 ítems (Cit en. García, Bernal, Lara y Galán, 2013).

Para su validación en la Universidad de Sevilla se reunió a dos expertos del área de organización de empresas, dos del área de educación física y deportes y tres gerentes de instalaciones deportivas posteriormente, se solicitó de nuevo a un grupo de cinco clientes de estas organizaciones que se lo leyeran y dijeran si entendían y podrían contestarlo correctamente. Finalmente, y al comprobar que no generaba dudas ni problemas de comprensión, se optó por utilizar dicho instrumento (García et al., 2013).

De otro lado, para la validación interna del instrumento se realizó un análisis factorial exploratorio sobre los 15 ítems de la escala de calidad percibida por el método de extracción de componentes principales y posterior rotación Varimax. Previamente, se calculó la medida de adecuación muestral de Kaiser -Meyer-Olkin (KMO) y el test de esfericidad de Barlett, mostrando en el primer caso un valor de .880 y el segundo estadísticamente significativo (X105 =8327.336; $\mathrm{p}<.001$ ), por lo que dicho análisis era pertinente. El AFE resultó en 3 dimensiones (instalaciones, personal y programa) que explicaron el 76.53\% del total de la varianza. La dimensión instalación se compuso de los ítems del 1 al 5, la dimensión personal del 6 al 10, y programas del 11 al 15. En relación a la escala de fidelidad, el AFE resultó en un solo factor que explicó el 
$87.05 \%$ de la varianza total, obteniendo un valor de .841 para Kaiser-MeyerOlkin y significativo en el test de esfericidad de Barlett (X6=2583.276; p < .001). (García et al., 2013).

La recolección de los datos se realizó en primer lugar mediante una reunión informativa con la dirección o gerencia del gimnasio, además se solicitó el permiso para acceder a las instalaciones y gestionar los cuestionarios, Anexo 2.

Para la aplicación de los cuestionarios se tuvieron en cuenta los diferentes horarios utilizados por los usuarios es decir durante toda la jornada dentro del gimnasio y se les aplicó una vez finalizada su práctica de actividad física. El diligenciamiento fue administrado por parte del equipo investigador, en un tiempo estimado de 6 a 7 minutos.

En relación al análisis de datos, se tomó la información correspondiente a las características de la población (muestra), utilizando para ello medidas de tendencia central y de dispersión, así como, las figuras respectivas.

\subsubsection{EVALUACIÓN BIOÉTICA}

Según la clasificación de riesgo presente en la resolución 8430 para investigaciones con seres humanos, esta investigación se clasificó sin riesgo, ya que no se realizó ninguna intervención o modificación intencionada de las variables biológicas, fisiológicas, sicológicas o sociales de los individuos que participaron en el estudio, para lo cual se contó con la aprobación del Comité de Bioética de la Universidad Tecnológica de Pereira (CBE-UTP). 


\subsection{RESULTADOS Y ANÁLISIS}

Tabla 1. Distribución de los participantes según género, edad, formación académica, ocupación, estado civil y rango salarial.

\begin{tabular}{|c|c|c|c|}
\hline \multicolumn{2}{|c|}{ Variables } & $\mathrm{n}$ & $\begin{array}{c}\text { Porcentaje } \\
\%\end{array}$ \\
\hline \multirow[b]{3}{*}{ Género } & Hombre & 1105 & 52,6 \\
\hline & Mujer & 995 & 47,4 \\
\hline & Total & 2100 & 100,0 \\
\hline \multirow{6}{*}{ Edad } & Entre 20 y menos años & 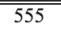 & 26,5 \\
\hline & Entre 21 y 40 años & 1213 & 57,7 \\
\hline & Entre 41 y 60 años & 311 & 14,8 \\
\hline & Entre 61 y más años & 18 & 0,9 \\
\hline & No responde & 3 & 0,1 \\
\hline & Total & 2100 & 100,0 \\
\hline \multirow{7}{*}{ Formación académica } & Primaria & 39 & "1,8 \\
\hline & Secundaria & 728 & 34,7 \\
\hline & Universitaria & 1063 & 50,6 \\
\hline & Especialización & 197 & 9,3 \\
\hline & Maestría & 65 & 3,2 \\
\hline & Doctorado & 8 & 0,4 \\
\hline & Total & 2100 & 100,0 \\
\hline \multirow{7}{*}{ Ocupación } & Estudiante & 742 & 35,3 \\
\hline & Empleado Privado & 501 & 23,8 \\
\hline & Independiente & 482 & 23 \\
\hline & Funcionario & 215 & 10,2 \\
\hline & Otro & 106 & 5,1 \\
\hline & Desempleado & 54 & 2,6 \\
\hline & Total & 2100 & 100,0 \\
\hline \multirow{7}{*}{ Estado civil } & Soltero & 1333 & 63,5 \\
\hline & Casado & 533 & 25,4 \\
\hline & Otro & 234 & 11,1 \\
\hline & Total & 300 & 100,0 \\
\hline & 1 salario Mínimo & 761 & 36,2 \\
\hline & 2 y 3 salarios mínimos & 921 & 43,8 \\
\hline & 4 y 5 salarios mínimos & 137 & 6,5 \\
\hline \multirow{3}{*}{ Rango salarial } & $\begin{array}{l}\text { Más de } 6 \text { salarios } \\
\text { mínimos }\end{array}$ & 8 & 0,5 \\
\hline & Otro & 273 & 13 \\
\hline & Total & 2100 & 100,0 \\
\hline
\end{tabular}

Fuente: elaboración propia

El perfil socio - demográfico de los usuarios de los gimnasios presenta diferencia de 110 personas entre el género masculino y femenino con predominio de hombres en los gimnasios. Este dato demográfico está en consonancia con la teoría de la psiquiatra Olga Albornoz, al plantear que desde el pasado los hombres eran los cazadores y siempre se les exigía mejor condición física, mientras que las mujeres eran recolectoras, y se ocupaban de otras actividades (Albornoz, 2010) Citado por Millán (2012) por consiguiente, por la historia genética el hombre da mayor importancia a la condición física. Mientras 
que en las mujeres las obligaciones laborales y la crianza de los hijos ocupan mayor parte de su tiempo, según lo dice Mónica Santa María (Investigadora del sensor). Al mismo tiempo, los hombres son más activos frente al deporte, se preocupan más por aumentar la masa muscular, mientras que las mujeres frecuentan los gimnasios con una intencionalidad más orientada hacia las actividades grupales.

El rango de edad predomínate se encuentra entre los 21 a 40 años (57.7\%), el menor porcentajes es de 60 años en adelante $0.9 \%$, que corresponden con la etapa de mantenimiento de las capacidades básicas como la fuerza resistencia y velocidad entre otras y evitar la pérdida de estas. Otra razón es el interés por una buena condición física y de salud, así como, la imagen. Al respecto, algunos estudios como el de Barba, Muñoz, y López, (2014) y Benel, Campos y Cruzado (2013), coinciden en que por lo regular los adolescentes, son quienes más valor dan a la percepción de la imagen corporal, lo cual va disminuyendo conforme avanza la edad. Por tanto, los datos de la investigación tienen coherencia con la teoría, al identificar las edades que predominan en los usuarios de los gimnasios.

Por otra parte, con respecto a la formación académica, quiénes más frecuentan los gimnasios son las personas con nivel universitario (50,6\%), seguido por las personas con formación secundaria (34,7\%), encontrando la menor proporción entre las personas con formación primaria $(1,8 \%)$ y con formación doctoral (0.4\%). De acuerdo con los datos los universitarios son más activos, porque en su rango de edad se tiene mayor conciencia e interés por los beneficios sociales, estéticos y de salud, por ende, disponen el tiempo para esto.

El 35,3\% de los usuarios de los gimnasios son estudiantes, seguido de trabajadores en empresas privadas $(23,8 \%)$, mientras que el porcentaje de usuarios desempleados $(2,6 \%)$ es el menor. Algunos factores que inciden en este resultado son la capacidad de pago y la distribución de tiempo de acuerdo con el nivel de importancia otorgado a la práctica de actividad física.

Adicionalmente la población soltera es la que asiste en mayor porcentaje $(63,5 \%)$ a los gimnasios, debido a que quieren mejorar su aspecto físico y la sensación de estar saludables y activos, también asisten por gusto y 
porque los entrenamientos y métodos utilizados son novedosos y atractivos, representando reto para sus vidas, lo que se relaciona con el rango de edad que predomina en los usuarios ( 21 - 40 años) en cuyas edades las características mencionadas hacen parte de sus expectativas.

El $80 \%$ de los usuarios devengan entre 1 y 3 salarios mínimos mensuales legales vigentes (SMMLV), y un mínimo porcentaje devengan más de 6 SMMLV, posiblemente quienes tienen nivel de formación doctoral, tal como se representó en la tabla anterior. Este dato permite vislumbrar la proyección comercial de estos establecimientos. Cabe anotar que esta información abre la posibilidad para otros servicios por ofertar como las visitas domiciliarias y personalizados, orientados a aquellas personas que tienen la capacidad económica para cubrir su costo y que por razones de tiempo y ocupaciones prefieren tener sus propios métodos para la realización del ejercicio con instructores particulares.

\subsubsection{VARIABLE SOCIODEMOGRÁFICA.}

Tiempo de vinculación en el gimnasio

\begin{tabular}{|l|r|}
\hline $\begin{array}{l}\text { Tiempo de } \\
\text { permanencia }\end{array}$ & $\begin{array}{l}\text { Número de } \\
\text { clientes }\end{array}$ \\
\hline Entre 1 y 12 meses & 1448 \\
\hline Entre 13 y 24 meses & 366 \\
\hline Entre 25 y 36 meses & 141 \\
\hline Más de 36 meses & 145 \\
\hline
\end{tabular}

\subsubsection{FRECUENCIA DE ASISTENCIA.}

Tabla 2. Usuarios de gimnasios y centros de acondicionamiento físico según frecuencia de asistencia. Pereira, 2017.

\begin{tabular}{|l|l|l|l|l|l|l|l|l|}
$\begin{array}{l}\text { Frecuencia } \\
\text { semanal }\end{array}$ & $\begin{array}{l}\mathbf{5} \\
\text { días }\end{array}$ & $\begin{array}{l}\mathbf{4} \\
\text { días }\end{array}$ & $\begin{array}{l}\mathbf{3} \\
\text { días }\end{array}$ & $\begin{array}{l}\mathbf{6} \\
\text { días }\end{array}$ & $\begin{array}{l}\mathbf{2} \\
\text { días }\end{array}$ & $\begin{array}{l}7 \\
\text { días }\end{array}$ & $\begin{array}{l}\mathbf{1} \\
\text { día }\end{array}$ & $\begin{array}{l}\text { TOTA } \\
\text { L }\end{array}$ \\
\hline $\mathbf{N}^{\circ}$ Clientes & 767 & 530 & 353 & 292 & 83 & 56 & 19 & 2100
\end{tabular}

Fuente: elaboración propia 
Figura 7. Usuarios de gimnasios y centros de acondicionamiento físico según frecuencia de asistencia. Pereira, 2017.

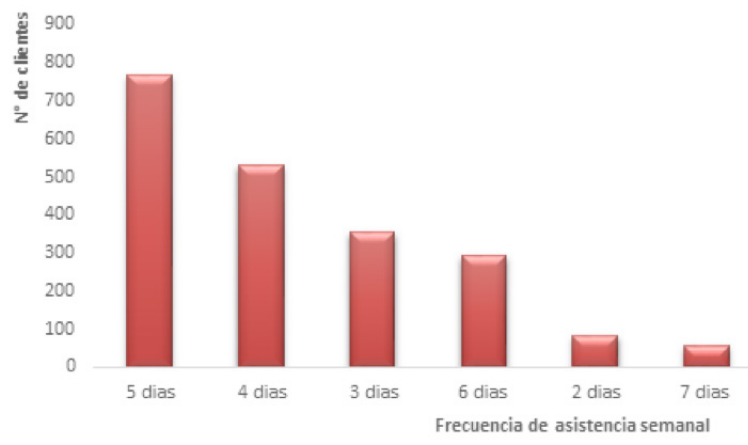

Fuente: elaboración propia

\subsubsection{DURACIÓN DE LA SESIÓN.}

Tabla 3. Usuarios de gimnasios y centros de acondicionamiento físico según duración de la sesión de entrenamiento. Pereira, 2017.

\begin{tabular}{|c|c|c|c|c|}
\hline $\begin{array}{l}\text { Duración de la } \\
\text { sesión }\end{array}$ & $\begin{array}{l}1 \text { hora o } \\
\text { menos }\end{array}$ & $\begin{array}{l}\text { Entre } 1 \text { y dos } \\
\text { horas }\end{array}$ & $\begin{array}{l}\text { Más de } 2 \\
\text { horas }\end{array}$ & \begin{tabular}{|l} 
TOTA \\
L
\end{tabular} \\
\hline $\mathbf{N}^{\circ}$ Clientes & 386 & 1566 & 148 & 2100 \\
\hline
\end{tabular}

Fuente: elaboración propia

Figura 8. Usuarios de gimnasios y centros de acondicionamiento físico según duración de la sesión de entrenamiento. Pereira, 2017.

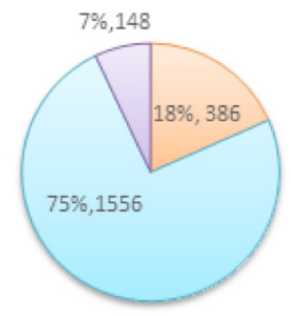

$\square 1$ horao menos $\square$ Entre 1 y doshoras $\quad \square$ Masde 2 horas

Fuente: elaboración propia 
El 69\% de los usuarios de los gimnasios de Pereira permanecen afiliados a estos centros alrededor de un año, el 7\% permanece más de 36 meses, lo que demuestra que el grado de fidelización de clientes es medio, presentando rotación considerable de usuarios. Por su parte el 78.5\% de ellos asisten con una frecuencia semanal de 3 a 5 días a la semana, en tal sentido cumplen con lo establecido por la OMS con relación al tiempo de dedicación a la actividad física semanal en favor de la salud que recomienda acumular mínimo 150 minutos de actividad física moderada a intensa a la semana (Organización Mundial de la Salud, 2010), así mismo el 74,5\% destinan entre 1 y 2 horas de tiempo en cada sesión.

Figura 9. Usuarios de gimnasios y centros de acondicionamiento físico según actividades que realiza. Pereira, 2017.
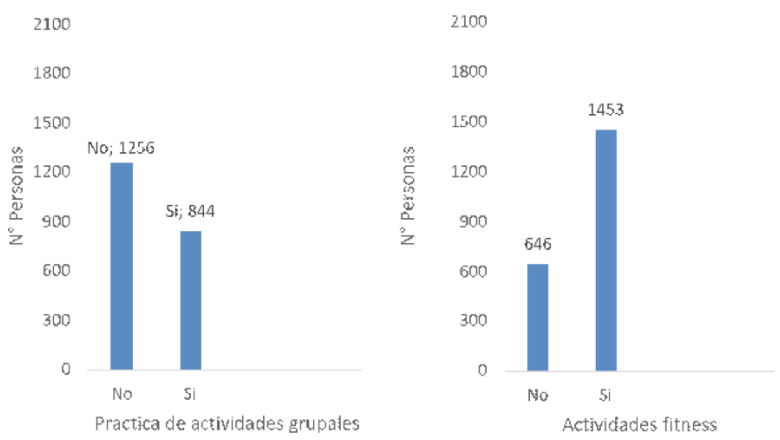

Fuente: elaboración propia

Entre los 2100 usuarios de los gimnasios se identificó que 1453 personas prefieren la práctica de actividades fitness, mientras que 844 personas practican actividades grupales. El resultado es el reflejo de la mayor asistencia de hombres a los establecimientos, pues estos prefieren actividades individuales y específicas, enfocadas en trabajar los aspectos que ellos quieren lograr. No obstante, se reconocen una serie de nuevas tendencias y modas que reflejan un interés por participar en actividades grupales sin distinción de género, como el crossfit, por ejemplo. 


\subsubsection{VARIABLE CALIDAD.}

\subsubsection{DIMENSIÓN CALIDAD DE LAS INSTALACIONES.}

Tabla 4. Usuarios de gimnasios y centros de acondicionamiento físico según calidad de las instalaciones. Pereira, 2017.

\begin{tabular}{l|r|r|r|r|r|r|r|r|r|c}
$\begin{array}{c}\text { ASPECTOS/CALIFI I I } \\
\text { CACIÓN }\end{array}$ & $\mathbf{1}$ & $\mathbf{2}$ & $\mathbf{3}$ & $\mathbf{4}$ & $\mathbf{5}$ & $\mathbf{6}$ & $\mathbf{7}$ & $\mathbf{8}$ & $\mathbf{9}$ & $\begin{array}{c}\text { TOTA } \\
\mathbf{L}\end{array}$ \\
\hline Atractivas & 4 & 3 & 38 & 67 & 115 & 200 & 405 & 482 & 758 & 2100 \\
\hline Espaciosas & 5 & 1 & 74 & 72 & 145 & 279 & 397 & 486 & 623 & 2100 \\
\hline Limpias & 1 & 8 & 22 & 48 & 57 & 120 & 274 & 543 & 1027 & 2100 \\
\hline Buenas condiciones & 2 & 7 & 38 & 47 & 84 & 149 & 316 & 555 & 902 & 2100 \\
\hline Ambiente & 4 & 9 & 34 & 45 & 114 & 170 & 327 & 526 & 871 & 2100
\end{tabular}

Fuente: elaboración propia

Figura 10. Usuarios de gimnasios y centros de acondicionamiento físico según calidad de las instalaciones. Pereira, 2017.

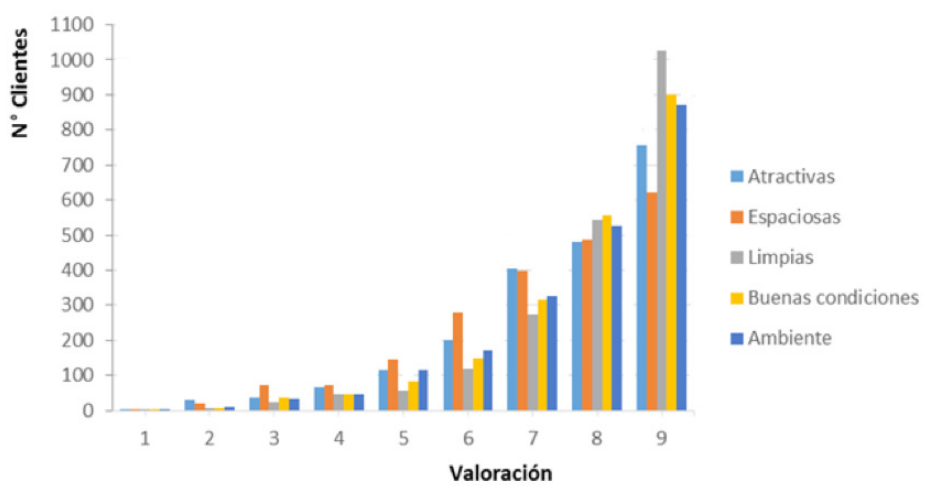

Fuente: elaboración propia

Los 5 aspectos que conforman la dimensión fueron evaluados con las dos puntuaciones más altas en la escala ( 8 y 9), el 59\% de los usuarios consideran que las instalaciones son atractivas, el 74,7\% encuentran muy buen ambiente, mientras que el aspecto menos favorable sin ser negativo fue el espacio de estos centros. 
Por consiguiente, la calidad de las instalaciones de estos establecimientos se percibe en buenas condiciones por parte de los usuarios para realizar las actividades.

Con referencia a lo anterior es importante destacar que "Las instalaciones y el equipamiento son los aspectos tangibles de la organización y son relevantes en servicios deportivos ya que el cliente conoce de forma detallada las condiciones de las instalaciones" (Mañas Rodríguez, Giménez Guerrero y Muyor Rodríguez, 2007).

\subsubsection{DIMENSIÓN CALIDAD DE LOS EMPLEADOS.}

Tabla 5. Usuarios de gimnasios y centros de acondicionamiento físico según calidad de los empleados. Pereira, 2017.

\begin{tabular}{l|r|r|r|r|r|r|r|r|r|r}
$\begin{array}{c}\text { ASPECTOS/CALIFICACIÓ } \\
\text { N }\end{array}$ & $\mathbf{1}$ & $\mathbf{2}$ & $\mathbf{3}$ & $\mathbf{4}$ & $\mathbf{5}$ & $\mathbf{6}$ & $\mathbf{7}$ & $\mathbf{8}$ & $\mathbf{9}$ & $\begin{array}{c}\text { TOTA } \\
\mathbf{L}\end{array}$ \\
\hline Respuesta rápida & & & & & & & & & & 1 \\
& 7 & 1 & 4 & 6 & 11 & 27 & 56 & 100 & 2100 \\
\hline Entusiasmo & 2 & 8 & 2 & 3 & 5 & 95 & 22 & 56 & 109 & 2100 \\
& & & 9 & 4 & 7 & & 3 & 1 & 1 & \\
\hline Educación & 1 & 4 & 1 & 3 & 4 & 84 & 18 & 47 & 126 & 2100 \\
& & & 6 & 3 & 3 & & 0 & 0 & 9 & \\
\hline Comodidad & 2 & 4 & 2 & 3 & 5 & 91 & 22 & 53 & 113 & 2100 \\
& & & 8 & 0 & 4 & & 0 & 4 & 7 & \\
\hline Experticia & 2 & 5 & 2 & 3 & 7 & 10 & 26 & 56 & 103 & 2100 \\
& & & 2 & 7 & 3 & 0 & 4 & 1 & 6 &
\end{tabular}

Fuente: elaboración propia

Figura 11. Usuarios de gimnasios y centros de acondicionamiento físico según calidad de los empleados. Pereira, 2017.

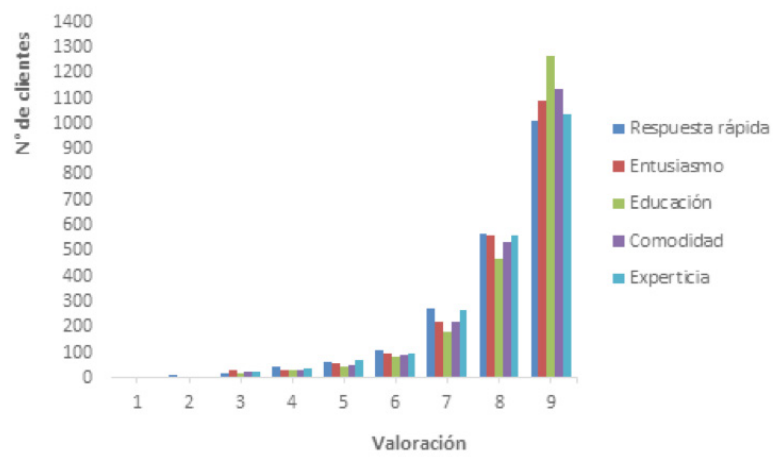

Fuente: elaboración propia 
Es de resaltar la alta calificación que obtuvo esta dimensión, concentrando la mayoría de respuestas en los puntos máximos de la escala, las personas encuestadas reconocen el alto nivel en la educación de los colaboradores y con 260 puntos menos la respuesta rápida es el aspecto con menor calificación, cabe anotar la buena apreciación de los usuarios frente a su experticia reflejándose en el entusiasmo que les transmiten, propiciando comodidad en los usuarios.

Es importante anotar que interacción social en los servicios es mucho más importante que los aspectos físicos o tangibles (Mañas et al. 2007).

En términos generales una menor cantidad de encuestados muestran inconformidad frente a la labor de los trabajadores.

Igualmente en servicios deportivos los clientes valoran sobre todo la eficacia en la respuesta del empleado (Mañas et al. 2007), debido a que la calidad humana del personal con el que cuentan los centros deportivos contribuye a marcar diferencias y a generar preferencias entre los usuarios que los frecuentan.

\subsubsection{DIMENSIÓN CALIDAD DE LOS PROGRAMAS}

Tabla 6. Usuarios de gimnasios y centros de acondicionamiento físico según calidad de los programas. Pereira, 2017.

\begin{tabular}{l|c|c|c|c|c|c|c|c|c|r} 
ASPECTOS/CALIFICACIÓN & $\mathbf{1}$ & $\mathbf{2}$ & $\mathbf{3}$ & $\mathbf{4}$ & $\mathbf{5}$ & $\mathbf{6}$ & $\mathbf{7}$ & $\mathbf{8}$ & $\mathbf{9}$ & TOTAL \\
\hline Energía & 2 & 5 & 17 & 23 & 36 & 70 & 167 & 508 & 1272 & 2100 \\
\hline Salud & 2 & 5 & 17 & 20 & 38 & 57 & 134 & 402 & 1425 & 2100 \\
\hline Humor & 3 & 2 & 8 & 20 & 40 & 60 & 152 & 422 & 1393 & 2100 \\
\hline Bienestar psicológico & 3 & 3 & 15 & 17 & 36 & 66 & 140 & 451 & 1369 & 2100 \\
\hline Condición física & 3 & 1 & 12 & 24 & 28 & 70 & 122 & 407 & 1433 & 2100
\end{tabular}

Fuente: elaboración propia 
Figura 12. Usuarios de gimnasios y centros de acondicionamiento físico según calidad de los programas. Pereira, 2017.

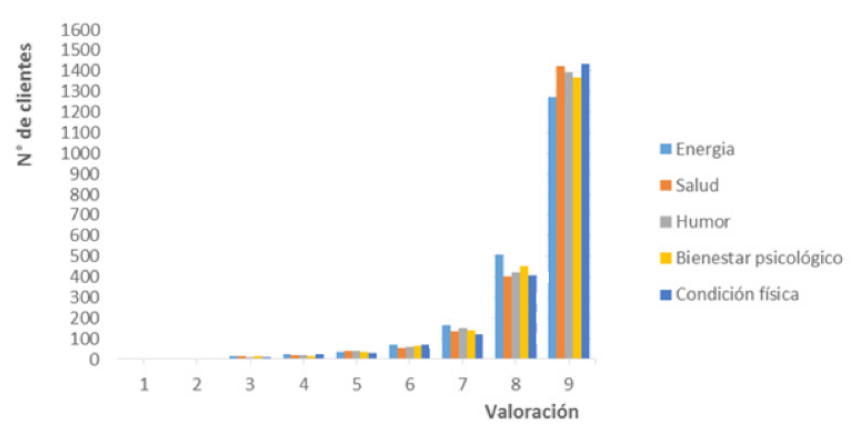

Fuente: elaboración propia

$\mathrm{Al}$ evaluar esta dimensión, se encontró que es en la que se agrupa el mayor número de respuestas en la escala 9, los encuestados están de acuerdo en que la calidad de los programas les ayuda en su bienestar físico y psicológico por tanto, la valoración que hace del servicio recibido se soporta en la excelencia de los programas, que a la vez son orientados por personal que se considera en su mayoría apto (figura 11), en cuanto a su conocimiento, empatía y actitud frente al usuario lo cual contribuye a la adherencia de los usuarios al centro.

\subsubsection{ANÁLISIS GENERAL DE LA VARIABLE CALIDAD.}

En términos generales la variable obtuvo la máxima calificación por parte de los usuarios, encontrando que la calidad de los programas en lo que respecta a los beneficios percibidos por parte de los usuarios y la calidad de los empleados es la más apreciada seguido por la calidad de las instalaciones, esta última debe la menor calificación a que los usuarios consideran que son poco espaciosas, no obstante este aspecto es subsanado por el grado de satisfacción que estos refieren en los otros 2 aspectos.

En efecto otras investigaciones demuestran que aspectos palpables como la habilidad de los colaboradores, sus actitudes y las instalaciones determinan la calidad de los servicios percibidos (Afthinos et al., 2005). En relación con este último, de acuerdo con los datos obtenidos los usuarios de los gimnasios pereiranos le asignan gran importancia a los beneficios recibidos por medio de los programas de acondicionamiento y entrenamiento físico. 
De acuerdo con lo que se ha venido analizando, es importante el nivel de atención que logren dar los empleados a los usuarios de los gimnasios, esto marcará la diferencia en atención y la calidad del talento humano que requieran estas organizaciones, porque generará en los usuarios mayor satisfacción y fidelización como resultado de la preferencia por el centro deportivo, así como, aumento de la población vinculada.

\subsubsection{VARIABLE CALIDAD GENERAL.}

Tabla 7. Usuarios de gimnasios y centros de acondicionamiento físico según calidad general de los programas y servicios. Pereira, 2017.

\begin{tabular}{l|c|c|c|c|c|c|c|c|c|r} 
ASPECTOS/CALIFICACIÓN & $\mathbf{1}$ & $\mathbf{2}$ & $\mathbf{3}$ & $\mathbf{4}$ & $\mathbf{5}$ & $\mathbf{6}$ & $\mathbf{7}$ & $\mathbf{8}$ & $\mathbf{9}$ & TOTAL \\
\hline Programas excelentes & 2 & 3 & 15 & 25 & 61 & 141 & 410 & 699 & 744 & 2100 \\
\hline Programas de nivel alto & 2 & 9 & 17 & 35 & 71 & 176 & 460 & 704 & 626 & 2100 \\
\hline Servicios de nivel alto & 3 & 5 & 24 & 38 & 74 & 156 & 460 & 707 & 633 & 2100
\end{tabular}

Fuente: elaboración propia

Figura 13.Usuarios de gimnasios y centros de acondicionamiento físico según calidad general de los programas y servicios. Pereira, 2017.

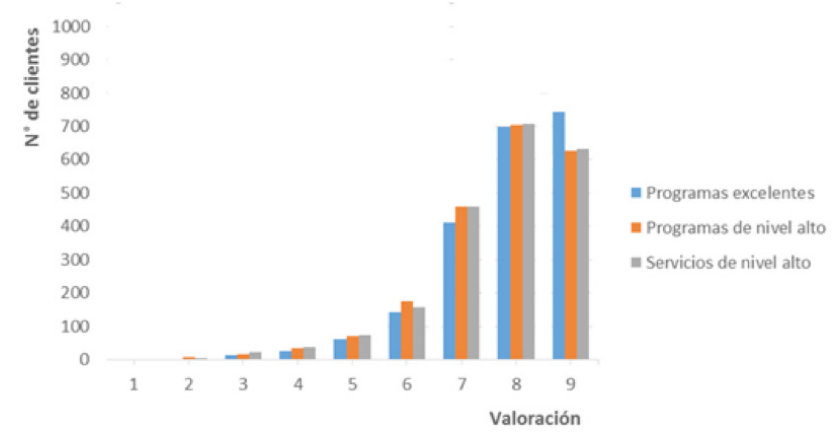

Fuente: elaboración propia

Al analizar la calidad técnica de los programas se encuentra la mayor valoración en la escala 8 y un alto porcentaje en la escala 9. No obstante, se debe tener claro que la definición de la calidad percibida ha sido el tema más debatido y con mayores controversias de la literatura del marketing (Brady y Conin, 2001). El término calidad percibida goza de diferentes conceptualizaciones sin existir una definición generalizada. Para ilustrar esto Zeithaml la interpreta 
como la apreciación de la excelencia de los productos o servicios que tiene el consumidor, o la percepción de superioridad que tiene el usuario sobre una organización y sus servicios ofertados (Cit en. García et al., 2013).

De acuerdo con los planteamientos teóricos se confirman los hallazgos de la investigación, en efecto el 63,3\% de los usuarios consideran que los programas y servicios son de alto nivel y el $68,7 \%$ refieren que los programas son excelentes, lo que da una alta valoración a este servicio.

En consonancia con Trujillo y Martínez (2009), se reconoce que los usuarios otorgan alta valoración en términos de calidad a lo que se les oferta en los gimnasios puesto que cada uno cuenta con características distintivas; por su parte Zeithaml y Bitner soportan la afirmación al manifestar que no hay programas ni servicios análogos debido a que son prestados por personas, con individualidades propias que imprimen su estilo particular al desempeñarse en la instrucción de los entrenamientos, así como su experiencia, formación académica y las variaciones en su estado de ánimo. Enfrentado con la diversidad de usuarios o clientes que tienen exigencias diferentes y lo reflejan en su demanda de consumo (Cit en. Trujillo y Martínez, 2009).

Como resultado, a juicio de los investigadores, la calidad no solo está determinada por los programas y servicios estandarizados que oferta el centro, también por las características de los instructores, administrativos y de los clientes externos, como se evidenció anteriormente. De donde se desprenden ofertas únicas y variadas para los diferentes gustos y expectativas de consumo, así como la importancia de cualificar a los entrenadores o profesionales de estas áreas, en temas de gestión de las emociones y del talento humano.

Por lo tanto, la calidad ofrecida en los programas y servicios de los gimnasios va a determinar la preferencia de los clientes para seguir perteneciendo al centro deportivo o no. 


\subsubsection{VARIABLE VALOR.}

Tabla 8. Usuarios de gimnasios y centros de acondicionamiento físico según valor del servicio. Pereira, 2017.

\begin{tabular}{l|r|r|r|r|r|r|r|r|r|r} 
ASPECTOS/CALIFICACIÓN & $\mathbf{1}$ & $\mathbf{2}$ & $\mathbf{3}$ & $\mathbf{4}$ & $\mathbf{5}$ & $\mathbf{6}$ & $\mathbf{7}$ & $\mathbf{8}$ & $\mathbf{9}$ & TOTAL \\
\hline Gran valor & 3 & 2 & 4 & 5 & 12 & 15 & 36 & 66 & 64 & 2100 \\
& 2 & 4 & 2 & 0 & 4 & 7 & 0 & 9 & 2 & \\
\hline Merecimiento & 1 & 7 & 2 & 3 & 10 & 13 & 36 & 57 & 84 & 2100 \\
\hline Costo-beneficio & 1 & & 4 & 6 & 1 & 3 & 1 & 9 & 8 & \\
\hline Apreciación & 1 & 3 & 2 & 2 & 90 & 14 & 35 & 67 & 76 & 2100 \\
& 4 & & 2 & 8 & & 3 & 7 & 9 & 4 & \\
\hline & 1 & 3 & 4 & 5 & 12 & 15 & 38 & 57 & 60 & 2100 \\
& 2 & 3 & 3 & 2 & 6 & 9 & 6 & 6 & 2 &
\end{tabular}

Fuente: elaboración propia

Figura 14. Usuarios de gimnasios y centros de acondicionamiento físico según valor del servicio. Pereira, 2017.

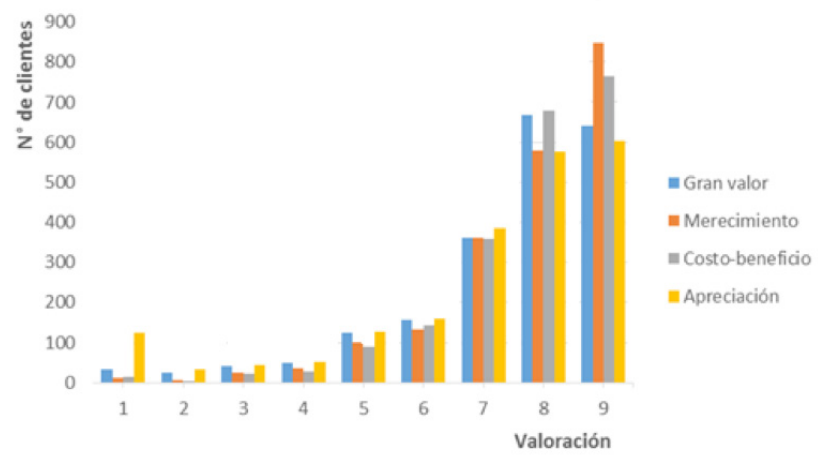

Fuente: elaboración propia

Esta variable al igual que las anteriores, concentra su calificación entre la escala 8 y 9 puesto que la población encuestada aprecia el servicio ofrecido en los gimnasios como de alto nivel, además que las actividades desarrolladas en los establecimientos son de gran valor porque en sus respuestas refieren buena consideración por lo recibido y manifiestan que están en total acuerdo con el costo de los servicios, puesto que, merece el precio asignado, ya que al ser tomados les generan valor de beneficio y merecimiento, de manera que la relación costo beneficio es equilibrada, generando sentido de satisfacción. 
La variable valor tiene estrecha relación con aspectos como la calidad de los servicios y programas y la satisfacción que generan. En este sentido, autores como Cronin, Brady y Hult (2000) sostienen que la valoración percibida tiene incidencia directa en la lealtad y filiación del usuario.

Por esta razón, y como resultado de la variada oferta de gimnasios y centros de acondicionamiento deportivo existentes, es creciente la importancia de fidelizar a los clientes del sector deportivo, donde el usuario es cada vez más practicante de actividad física como ya se ha referenciado en los informes Helsinki o Vocasport (European Conmmission, 1999). Atendiendo a esto, los anteriores resultados de la apreciación y buena consideración que tiene la población encuestada arrojan datos importantes para establecer pautas que mejoren la fidelidad en las instalaciones deportivas, puesto que como dijera García, Bernal, Lara \& otros: aspectos como la calidad y la valoración de lo recibido por parte del usuario, son elementos claves a tener en cuenta en las estrategias de fidelización. (García et al. 2013).

Por su parte Peiró, Martínez y Ramos (2005) confirmaron, desde la perspectiva del usuario y del empleado, dos grandes factores que inciden en la calidad del servicio, por ende, en la valoración o apreciación del usuario frente al centro y sus servicios, ellos se refieren a lo funcional y relacional. La primera tiene que ver con la atención eficiente del usuario frente a los aspectos fundamentales de los servicios. La segunda hace referencia al buen trato que experimenta el cliente, otorgándole beneficios emocionales. Estos aspectos son determinantes en el nivel de valoración del usuario y conducen a su permanencia a estos centros, así como un factor vinculante de entrada o de enganche en las primeras experiencias de los nuevos clientes en estos establecimientos(Mañas et al. 2007) 


\subsubsection{VARIABLE SATISFACCIÓN.}

Tabla 9. Usuarios de gimnasios y centros de acondicionamiento físico según satisfacción.

Pereira, 2017.

\begin{tabular}{l|r|r|r|r|r|r|r|r|r|r} 
ASPECTOS/CALIFICACIÓ & $\mathbf{1}$ & $\mathbf{2}$ & $\mathbf{3}$ & $\mathbf{4}$ & $\mathbf{5}$ & $\mathbf{6}$ & $\mathbf{7}$ & $\mathbf{8}$ & $\mathbf{9}$ & $\begin{array}{c}\text { TOTA } \\
\mathbf{L}\end{array}$ \\
$\mathbf{N}$ & 3 & 4 & 2 & 3 & 7 & 11 & 32 & 61 & 912 & 2100 \\
\hline Satisfacción de programas & 3 & 4 & 0 & 2 & 6 & 3 & 9 & 1 & & \\
\hline Felicidad & 4 & 5 & 2 & 2 & 6 & 12 & 32 & 61 & 906 & 2100 \\
& & & 6 & 1 & 7 & 5 & 8 & 8 & & \\
\hline Asociación & 1 & 5 & 1 & 2 & 4 & 11 & 30 & 58 & 100 & 2100 \\
\hline Decisión acertada & & & 6 & 7 & 4 & 7 & 6 & 4 & 0 & \\
& 0 & 3 & 1 & 3 & 5 & 89 & 29 & 59 & 101 & 2100 \\
& & & 6 & 1 & 8 & & 1 & 7 & 5 &
\end{tabular}

Fuente: elaboración propia

Figura 15. Usuarios de gimnasios y centros de acondicionamiento físico según satisfacción.

Pereira, 2017.

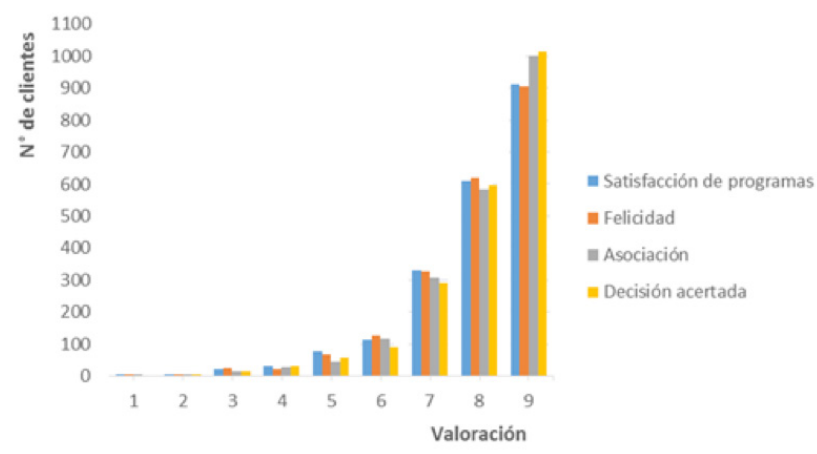

Fuente: elaboración propia

Los usuarios manifiestan satisfacción con lo recibido por parte de los centros deportivos como resultado de la complacencia de necesidades y expectativas. Por lo tanto, las personas están altamente complacidas con lo que se les ofrece. En lo que respecta a la vinculación al establecimiento deportivo el 76,2\% de los usuarios se sienten a gusto, al tiempo que consideran que su incorporación fue una decisión acertada. Igualmente, el 72,5\% se encuentran satisfechos con los programas y la felicidad que estos les generan. Gil et al., (2005) consideran que la satisfacción puede entenderse como "resultado de la percepción de valor" (p. 55). Es decir que refiere la percepción que se tiene de lo que se ha adquirido. 
De otro lado el porcentaje de insatisfacción en los encuestados es mínimo (alrededor del 25\%), no obstante, resulta oportuno considerar a profundidad las causas de este resultado, ya que la relación y grado de satisfacción de los usuarios con los programas es importante y define el nivel del servicio que se brinda, al tiempo que abre las puertas a la innovación, con el fin de tener a gusto la población cautiva y conseguir nuevos usuarios. De esto se desprende el aumento en la satisfacción del usuario, conducente al aumento de su lealtad, porque después de una experiencia insatisfactoria, se afecta el nivel de fidelidad con las empresas, en este caso con los establecimientos deportivos. (Elasri et al. 2015).

Además, la razón de que estos centros deportivos sean sostenibles y rentables es que el usuario conserve y mejore su condición física, a la par de mayores beneficios psicológicos, emocionales y sociales que mejoren su calidad de vida. Todo esto mediante servicios adquiridos a buen precio y en congruencia con lo que el centro le ofreció, lo que se refleja en mayor demanda y reconocimiento del centro deportivo.

\subsubsection{VARIABLE INTENCIÓN DE COMPRA.}

Tabla 10. Usuarios de gimnasios y centros de acondicionamiento físico según intención de compra. Pereira, 2017.

\begin{tabular}{l|r|r|c|c|c|c|c|c|c|r} 
ASPECTOS/CALIFICACIÓN & $\mathbf{1}$ & $\mathbf{2}$ & $\mathbf{3}$ & $\mathbf{4}$ & $\mathbf{5}$ & $\mathbf{6}$ & $\mathbf{7}$ & $\mathbf{8}$ & $\mathbf{9}$ & TOTAL \\
\hline Comentarios positivos & 4 & 6 & 14 & 22 & 52 & 94 & 261 & 563 & 1084 & 2100 \\
\hline Recomendación & 2 & 5 & 10 & 26 & 40 & 92 & 248 & 564 & 1113 & 2100 \\
\hline Permanencia & 4 & 2 & 15 & 17 & 51 & 87 & 242 & 552 & 1130 & 2100 \\
\hline Reinscripción & 20 & 13 & 14 & 34 & 50 & 106 & 232 & 503 & 1128 & 2100
\end{tabular}

Fuente: elaboración propia 
Figura 16. Usuarios de gimnasios y centros de acondicionamiento físico según intención de compra. Pereira, 2017.

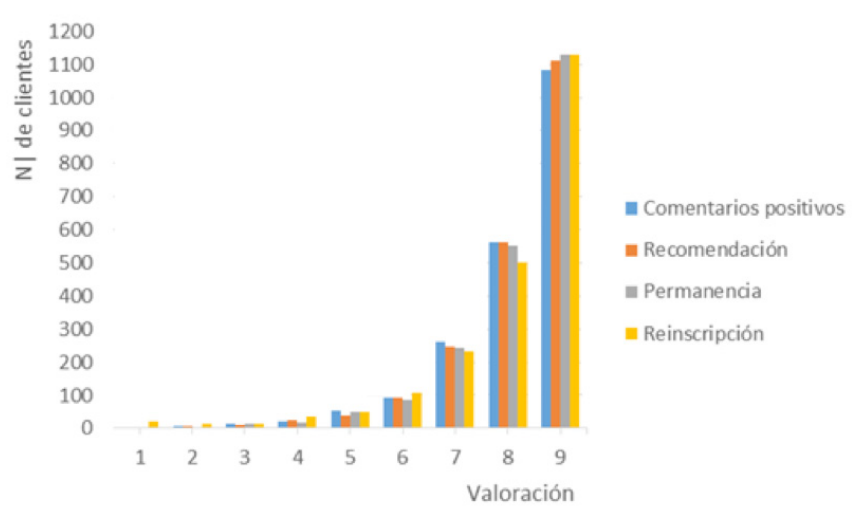

Fuente: elaboración propia

El mayor número de respuestas de los clientes $52 \%$, se concentraron en la máxima calificación de la escala (9), alrededor del 77,6 \% del total de usuarios están de acuerdo con el funcionamiento de los gimnasios en relación con sus experiencias personales, al punto de hacer comentarios positivos frente al servicio recibido. Por estas razones estarían de acuerdo en recomendarlo a terceros y seguirían asistiendo al centro deportivo. En cambio, una mínima cantidad de encuestados (23\%) respondieron que estaban en desacuerdo, lo que significa que la permanencia de los clientes y los comentarios que estos hagan del centro deportivo con personas externas, tienen que ver con buenos servicios, ambiente cálido y con un talento humano calificado, amable y comprometido con el centro y la buena atención a los clientes.

De otra parte, en atención a la calidad percibida por los usuarios se establece su permanencia, lo que genera mayor rendimiento económico, puesto que la alta rotación de usuarios frena el avance y continuidad de los procesos, ya que para el cliente interno se rompe la secuencia con el cliente, haciéndose necesario el inicio de procesos cada que se incorpora uno nuevo. Ahora bien, a pesar de la alta rotación de usuarios, los gimnasios y centros de acondicionamiento físico manejan un número estable de inscritos, sin embargo, en lo tocante a la sistematización de procesos que conducen a niveles más altos o especializados del servicio, no es posible que estos centros avancen, quedando en la fase de 
captación, adaptación y etapa inicial de entrenamientos específicos puesto que como se reflejó en el perfil sociodemográfico el mayor porcentaje de usuarios (69\%) permanece 1 año vinculado al establecimiento, y solo el 13.6\% llevan entre 2 y tres años.

Hechos como estos llevan a plantear que la fidelidad de los clientes está relacionada con el rendimiento y los beneficios, así como con la calidad percibida. Así pues, uno de los principales objetivos de las organizaciones para permanecer en el mercado actual es la fidelización de sus clientes. (García, Fernández y Bernal, 2014).

Lo dicho anteriormente es un riesgo para los gimnasios locales frente a las grandes plataformas que se están posicionando en el mercado local y nacional, las cuales cuentan con ventajas competitivas que las hacen más sólidos técnica y económicamente, frente a los gimnasios abordados en la investigación y que no han establecido estrategias contundentes para la intención de compra de los usuarios. En fin, la fidelidad está a expensas de la calidad. (García et al. 2014). 
CAPÍTULO III 


\section{CAPÍTULO III. CONCLUSIONES Y RECOMENDACIONES DE LA INVESTIGACIÓN}

\subsection{CONCLUSIONES}

De acuerdo a las características sociodemográficas de la población objeto de estudio, hay mayor participación de hombres con respecto a mujeres con $52.6 \%$. Las personas entre 21 y 40 años son las que más frecuentan el centro deportivo con un porcentaje de 57,8\%, agregando que de acuerdo a la formación académica prevaleció con porcentajes altos los universitarios con un $50,5 \%$, seguido de estudiantes de secundaria con un $34,7 \%$. De acuerdo a la ocupación son los estudiantes los que prevalecen con un 35,3\%. Por otro lado, con respecto al estado civil lo que se evidencio fue una mayor participación de solteros con un total de $63,5 \%$ frente a un $25,4 \%$ de casados. A lo anterior se le suma que el tiempo que realizan actividad física oscila entre los 90 a 120 minutos diarios.

Las necesidades y deseos de los clientes pueden verse afectadas por múltiples factores, la presente investigación busco entenderlos a partir de la identificación de su perfil sociodemográfico y la percepción de los servicios. Los resultados permiten ilustrar como las categorías de formación, ingresos y beneficios percibidos constituyen los factores de mayor influencia al momento de pensar en satisfacer las necesidades de los clientes. Además, permitió identificar la responsabilidad de las empresas del sector de la actividad fascia en el desarrollo de servicios que cumplan con las expectativas del cliente moderno, así como la importancia en la determinación del perfil y la segmentación de los servicios.

Los hallazgos apuntan a la satisfacción del usuario en relación al costo/calidad. Este aspecto, sumado a otros factores como la declaración por parte de los usuarios de haber realizado una buena elección con el centro, debido a que los servicios cuentan con un buen personal y los programas satisfacen sus necesidades. Adicionalmente, la mayoría de clientes expresan que volverían a elegir el centro deportivo y que están dispuestos a recomendar y difundir sus servicios, demostrando de este modo una fidelidad que guarda estrecha relación con la calidad percibida. 
Es posible identificar la asociación entre factores de percepción en los clientes en cuanto al desempeño de entrenadores, la satisfacción con los programas y los factores determinantes de la permanecía de los usuarios. Es posible observar mediante el uso de mediciones objetivas y análisis de contexto, que a pesar de la alta oferta y variedad de servicios de actividad física en la ciudad, la tasa de permanecía y frecuencia de los usuarios en los centros deportivos se encuentra entre media y alta (69\%), esto se relaciona con la alta satisfacción que presentan los clientes con los entorno físicos y las relaciones interpersonales con los entrenadores.

El presente documento intentó vislumbrar las características que los diseñadores de servicios de actividad física deberían tener en cuenta durante el proceso de creación de programas basados en el perfil del cliente. En general, este estudio indica que actualmente los aspectos técnicos como la percepción en la calidad de los programas se encuentra acorde a las necesidades de los usuarios en la ciudad, al considerar que los clientes los perciben como de buena calidad, dirigidos a mejorar la salud, el aumento de la energía, bienestar psicológico, mejoramiento del nivel de condición física e incremento de la calidad de vida.

\subsection{RECOMENDACIONES}

Uno de los aspectos importantes es generar programas que motiven la realización de actividad física en los adultos mayores, programas de actividades dirigidas especialmente para ellos para el mejoramiento y prevalencia de la salud de los mismos. Aunque en su mayoría se cuenta con buena participación de jóvenes, también se deben mejorar en programas que motiven a las personas mayores a realizar actividad física.

Innovar con diferentes estrategias que motiven a los usuarios a seguir en los establecimientos, realizar charlas de interés para los usuarios, ya que si se demuestra que el gimnasio se preocupa por su bienestar, se creará mayor fidelidad en estos.

Planear actividades que generen la integración entre los usuarios de los gimnasios, lo que demuestra la importa que estos centros otorgan a su bienestar y el interés porque estén a gusto con los servicios que perciben. 
Implementar las Tic como estrategias de mercadeo y fidelización de los usuarios, para consolidar bases de datos con su información, así como la actualización permanente de las mismas, incluyendo historia y seguimiento de la condición física.

Conservar contacto con los usuarios/clientes que abandonan el servicio, así como, con usuarios/clientes potenciales para compartir ofertas que los cautiven y motiven a tomar o retomar el servicio, al tiempo que se les pregunte por sus percepciones u opiniones que puedan mejorar el servicio de los gimnasios.

Realizar estudios de satisfacción de los clientes cada tres años lo cual servirá de referencia si se han mejorado los servicios, o si, por el contrario, hay aspectos por mejorar. 


\section{BIBLIOGRAFÍA}

Albornoz, O. (2010). El Sensor Yanbal de la Mujer Colombiana 2012 revela cifras de la actividad fisica en Colombia. En línea, consultado el 2 de marzo de 2019. disponible en: https://www.eltiempo.com/archivo/documento/CMS11507364

Alexandris, K.; Douka, S.; Papadopoulos, P. y Kaltsatou, A. (2008). Testing the role of service quality on the development of brand associations and brand loyalty. Managing Service Quality, 18(3): 239-254.

Afthinos, Y., Theodorakis, N., \& Nassis, P. (2005). Customers' expectations of service in Greek fitness centers: Gender, age, type of sport center, and motivation differences. Managing Service Quality: An International Journal. , 15 (3) 245-258.

Barba, A., Muñoz, O. y López, A. (2014). La práctica corporal y la imagen corporal: reconstruyendo significados. Revista Electrónica Interuniversitaria de Formación del Profesorado,17(1), 163-176.

Benel, R., Campos, S., y Cruzado, L. (2013). Insatisfacción corporal en estudiantes de medicina de la Universidad Peruana Cayetano Heredia medida con el Body Shape Questionnaire. Revista de Neuro-Psiquiatría, 75(3), 85-92.

Bouchet, P., Bodet, G., Bernache-Assollant, I. and Kada, F. (2011). Segmenting sport spectators: Construction and preliminary validation of the Sporting Event Experience Search (SEES) scale. Sport Management Review, 14, 42-53.

Boubeta, A., Fernández, D., Boubeta, J., Prado, E., y Mallou, J. (2009). Un intento de segmentación integral de los usuarios de centros deportivos. Apunts Educación Física y Deportes, (95), 82-91

Brady, M., \& Cronin, J. (2001). Some new thoughts on conceptualizing perceived service quality: a hierarchical approach. Journal of marketing, 65(3) 34-49. 
Calabug, F., Crespo, J., \& Mundina, J. (2012). Efecto del coste percibido, la calidad del servicio y la satisfacción dobre las intenciones futuras del espectador. Estudios de economía aplicada, 30(2).

Casas, A. (2004). Actividad física habitual de los adolescentes de la región de Murcia. Análisis de los motivos de práctica y abandono de la actividad físico-deportiva. En línea consultado del 3 de mayo de 2019. Disponible en: https://www.efdeportes.com/efd107/motivos-de-practica-y-abandono-de-laactividad-fisico-deportiva.pdf

Chen, Z., y Dubinsky, A. (2003). A conceptual model of perceived customer value in e-commerce: A preliminary investigation. Psychology and Marketing, 20(4) 323-347.

Coldeportes (2009). Plan Decenal del deporte, la recreación, la educación física y la actividad física 2009 - 2019. En línea, consultado el 4 de abril de 2019. Disponible en: http://www.coldeportes.gov.co/planeacion gestion_control/modelo_integrado_planeacion_gestion/planeacion/largo_ plazo/57928\&download $=\mathrm{Y}$

Congreso de la República de Colombia. (2016). Diario Ofcial de la República de Colombia. Bogota, Colombia.

Congreso de la República de Colombia (1991). Constitución Politica de Colombia. Constituyente, Asamblea Nacional. Bogota. En línea, consultado el 8 de febrero de 2019. disponible en: http://pdba.georgetown.edu/Constitutions/ Colombia/colombia91.pdf

Congreso de la República de Colombia (21 de diciembre de 2001). Ley 715. En línea, consultado el 3 de marzo de 2019. Disponible en: https://www. mineducacion.gov.co/1621/articles-86098_archivo_pdf.pdf

Congreso de Colombia. (18 de Enero de 1995). Ley 181. En línea, consultado el 3 de marzo de 2019. Disponible en: http://www.coldeportes.gov.co/ coldeportes/?idcategoria $=48993 \#$ 
Congreso de la República de Colombia. (3 de Diciembre de 2001). Ley 711 de 2001. En línea, consultado el 3 de marzo de 2019. Disponible en: http://www. secretariasenado.gov.co $: 1$

Congreso de la República de Colombia. (31 de Diciembre de 2001). Ley 729. Recuperado el 2012 de Abril de 12, de Secretaria del senado: http://www. secretariasenado.gov.co

Congreso de la República de Colombia (29 de julio de 2016). Ley 1801 de 2016. En línea, consultado el 3 de marzo de 2019. Disponible en: http://www. secretariasenado.gov.co/senado/basedoc/ley_1801_2016.html

Congreso de la República de Colombia (2 de mayo de 2017). Ley 1831. En línea, consultado el 4 de abril de 2019. Disponible en: https://dapre. presidencia.gov.co/normativa/normativa/LEY\%201831\%20DEL\%2002\%20 DE\%20MAYO\%20DE\%202017.pdf

Cronin, J., Brady, M., \& Hult, G. (2000). Assessing the effects of quality, value, and customer satisfaction on consumer behavioral intentions in service environments. Journal of retailing, 76(2) 193-218.

Díaz Sánches, C. (2011). Estado actual del sistema de regulacion pública sobre los establecimientos de comercio constituidos como gimnasios del municipio de Pereira. Medellin : Universidad de Antioquía .

Elasri, A., Triadó, T., y Aparicio, M. (2015). La satisfacción de los clientes de los centros deportivos municipales de Barcelona. Apunts. Educació Física i Esports, 2015, vol. 119, num. 1, p. 109-117.

Eropean Commission (1999). Informe de Helsinki sobre el deporte: La Comisión, partidaria de un nuevo enfoque. En línea, consultado el 3 de marzo de 2019. Disponible en: https://europa.eu/rapid/press-release_IP-99918_es.htm

Fernández, J., Ruiz, P., García, A., y Colón, L. (2016). El gasto económico en centros de fitness low-cost: Diferencias sgúun fidelidad y caracteristicas del cliente. . SPORT TK- Revista EuroAmericana de Ciencias del Deporte, 137144 . 
Garcia , J., Bernal , A., Lara, A., y Galan , P. (31 de agosto de 2013). La calidad de servicios percibida y su influencia en la fidelidad de usuarios mayores en centros de fitness publicos . Escritos de Psicologia , 6(2), 26-34.

García, J., Fernández, J., y Bernal, A. (2014). La percepción de calidad y fidelidad en clientes de centros de fitness lowcost. Suma Psicológica, 21(2), 123-130.

García, J., Fernández, J., Durán, J., y Vélez, L. (2015). La actividad en las redes sociales: Un estudio de caso en la industria del fitness. Nuevas tendecnias en educación física, deporte y recreación, (28), 44-49.

Gil, I., Sánchez, M., Berenguer, G. y González, M. (2005). Encuentro de servicio, valor percibido y satisfacción del cliente en la relación entre empresas. Cuadernos de Estudios Empresariales, 15, 47-72.

Gutiérrez Macías, L. (2004). Una mirada al ejercicio fisico en los gimnasios de Medellin desde la promoción de la salud y prevencion de la enfermeda primaria . Medellin: Universidad de Antioquía.

Hill, B. y Green, B. (2012). Repeat participation as a function of program attractiveness, socializing opportunities, loyalty and the sportscape across three sport facility contexts. Sport Management Review, 15(4): 485-499.

Kotler, P., y Armstrong, G. (2003). Fundamentos de marketing. Pearson Education.

Kotler, P. y Lee (2011), Marketing en el sector público, México: Fondo de cultura económica.

Mañas Rodríguez, M., Giménez Guerrero, G., y Muyor Rodríguez, J. (28 de Agosto de 2007). Los tangibles como predictores de la satisfacción del usuario en servicios deportivos. (U. Almería, Ed.) Psicothema, 20(2), 243-248.

Millán Caballero, R., Santana Lugones, J., y Escoriza Martínez, T. (2016). Fundamentos teóricospara la evaluación de la calidad de los servicios de alto rendimiento deportivo. arrancada, 16(29), 1-11. 
Nuviala, A., Pérez, R., Osuna, M., Grao, A., Nuviala, R., y Jurado, J. (2012). Calidad, satisfacción y valor percibido de los usuarios de un servicio deportivo público. Movimento, 18(4), 11-32.

Nuviola, A.(2013). Duration of membership at sports centers and reasons for quitting. Perceptual and Moor Skills, 117, 733-741.

Organización Mundial de la Salud. (2010). Recomendaciones mundiales sobre actividad física para la salud. En linea, consultado el 8 de febrero de 2019. Dispobible en: https://www.who.int/dietphysicalactivity/ publications/9789241599979/es/

Perea, L. (2013). Marketing para las nuevas tendencias en Fitness, salud y entrenamiento personal. Diputació de Barcelona.

Peiró, J., Martínez, V., y Ramos, J. (2005). Employees' overestimation of functional and relational service quality: A gap analysis. The Service Industries Journal, 25, 1-17.

Reverter, J., \& Barbany, J. (2007). Del gimnàs al lleure-salut. Centres de Fitness, Fitness Center, Fitness \& Wellness, Spa, Balnearis, Centres de Talassoteràpia, Curhotel. Apunts. Educació Física i esports, 59-68.

Rodríguez, J., Soto, C., Camacho, S., y Cantón, A. (2008). ). Posmodernidad y nuevas tendencias de práctica físico-deportiva: un análisis del modelo corporal narcisista en los centros deportivos municipales de Almería. Córdoba, 2-5 de abril de 2008: IV Congreso Internacional y XXV Nacional de Educación Física “los hombres enseñando aprenden". Séneca (Epst. 7, 8) (p. 20).

Sandoval, I. F. (2015). El marketing en el sector público: naturaleza, aplicaciones y desafíos. Revista Contribuciones a las Ciencias Sociales, (27).

Shonk, D., y Chelladurai, P. (2008). Service quality, satisfaction, and intent to return in event sport tourism. Journal of sport management, 22(5), 587-602.

Solar, L. (2003). Pierre de Coubertin la dimensión pedagógica. La aportación del movimiento olímpico a las pedagogías corporales. Madrid: Gymnos. 
Suresh, S.; Ravichandran, S. y Ganesan, P. (2011). Understanding wellness centre loyalty through lifestyle analysis. Health Marketing Quarterly, 28(1): 16-37.

Teixeira, M. \& Correia, A. (2009). Segmenting fitness centre clients. International Journal of Sport Management and Marketing, 5(4): 396-416.

Theodorakis, N., Howat, G., Ko, Y., y Avourdiadou, S. (2014). A comparison of service evaluation models in the context of sport and fitness centres in Greece. Managing Leisure, 19(1), 18-35.

Toro, V., y Pereira, R. (2013). Caracterización de los centros de acondicionamiento y preparación física de Risaralda en cuanto a recursos físicos, talento humano y servicios. Pereira: Universidad tecnológica de Pereira .

Trujillo, A., y Martínez, J. (2009). Compresión de la calidad en el servicio como la integración de dos dimensiones: tangible e intangible. (U. A. Bucaramanga, Ed.) Revista Colombiana de Marketing, 8(13), 59-67.

UNESCO (2013). Carta Internacional de la Educación Física, la Actividad Física y el Deporte. En línea, consultado el 12 de Junio de 2018. Disponible en: http://portal.unesco.org/es/ev.php-URL_ID=13150\&URL_DO=DO_ TOPIC\&URL_SECTION=201.html

UNESCO (2015). UNESCO.ORG Organización de las Naciones Unidas para le Educación, la Ciencia y la Cultura. En línea, consultado el 12 de Junio de 2018: http://portal.unesco.org/es/ev.php-URL_ID $=13150 \& U R L \_D O=D O \_$ TOPIC\&URL_SECTION=201.html

Vallejo, A. (2005). El usuario y la realidad jurídica de los CAPF y los gimnasios en el municipio de Medellín. Medellin: Universidad de Antioquia.

Zabala, J. (2008). 3-2 Ideas clave. El desarrollo de la competencia matemática (Vol. 7). Graó. 
ANEXOS 


\section{ANEXOS}

\section{A. Instrumento}

Estimado usuario, Agradecemos su voluntaria participación para diligenciar este cuestionario. Su respuesta no será en ningún momento identificado por lo que por favor no incluya su cédula ni su nombre en la encuesta. De igual forma la discusión de los resultados se realizará con el análisis de los datos del grupo. El tiempo estimado de realización del cuestionario es de 5-7 minutos.

Por favor, al finalizar el cuestionario devuélvalo al encuestador. Gracias por su colaboración.

\begin{tabular}{|c|c|c|c|c|c|}
\hline & & $\begin{array}{l}\text { alme } \\
\text { acu }\end{array}$ & & & $\begin{array}{r}\text { Totalmente de } \\
\text { acuerdo }\end{array}$ \\
\hline Las instalaciones del centro deportivo son atractivas. & 1 & 2 & 3 & $\begin{array}{lllll}4 & 5 & 6 & 78 & 9 \\
\end{array}$ & 9 \\
\hline Las instalaciones del centro deportivo son espaciosas. & 1 & 2 & 3 & $\begin{array}{cccccc}4 & 5 & 6 & 78 & 9 \\
\end{array}$ & 9 \\
\hline Las instalaciones del centro deportivo están limpias. & 1 & 2 & 3 & $\begin{array}{llllll}4 & 5 & 6 & 78 & 9\end{array}$ & 9 \\
\hline $\begin{array}{l}\text { El equipamiento del centro deportivo está en buenas } \\
\text { condiciones. }\end{array}$ & 1 & 2 & 3 & $\begin{array}{llllll}4 & 5 & 6 & 78 & 9\end{array}$ & 9 \\
\hline $\begin{array}{l}\text { El ambiente del centro deportivo (temperatura, iluminación, } \\
\text { ruido y olor) es bueno. }\end{array}$ & 1 & 2 & 3 & $\begin{array}{lllll}4 & 5 & 6 & 78 & 9\end{array}$ & 9 \\
\hline $\begin{array}{l}\text { Los empleados responden rápidamente a las necesidades de } \\
\text { los clientes. }\end{array}$ & 1 & 2 & 3 & $\begin{array}{lllll}4 & 5 & 6 & 78 & 9\end{array}$ & 9 \\
\hline Los empleados trabajan con entusiasmo. & 1 & 2 & 3 & $\begin{array}{lllll}4 & 5 & 6 & 78 & 9\end{array}$ & 9 \\
\hline Los empleados son educados. & 1 & 2 & 3 & $\begin{array}{llllll}4 & 5 & 6 & 7 & 8 & 9 \\
\end{array}$ & 9 \\
\hline Los empleados ayudan a que los clientes se sientan cómodos. & 1 & 2 & 3 & $\begin{array}{llllll}4 & 5 & 6 & 78 & 9\end{array}$ & 9 \\
\hline Los empleados son expertos. & 1 & 2 & 3 & $\begin{array}{llllll}4 & 5 & 6 & 78 & 9 \\
\end{array}$ & 9 \\
\hline Los programas de actividad fisica me ayudan a incrementar mi energia. & 1 & 2 & 3 & $\begin{array}{lllll}4 & 5 & 6 & 78 & 9 \\
\end{array}$ & 9 \\
\hline $\begin{array}{l}\text { Los programas de actividad física me ayudan a mejorar mi } \\
\text { salud. }\end{array}$ & 1 & 2 & 3 & $\begin{array}{llllll}4 & 5 & 6 & 78 & 9\end{array}$ & 9 \\
\hline $\begin{array}{l}\text { Los programas de actividad fisica me ayudan a mejorar mi } \\
\text { humor. }\end{array}$ & 1 & 2 & 3 & $\begin{array}{llllll}4 & 5 & 6 & 7 & 8 & 9\end{array}$ & \\
\hline $\begin{array}{l}\text { Los programas de actividad física me ayudan a mejorar mi } \\
\text { bienestar psicológico. }\end{array}$ & 1 & 2 & 3 & $\begin{array}{lllll}4 & 5 & 6 & 78 & 9\end{array}$ & 9 \\
\hline $\begin{array}{l}\text { Los programas de actividad fisica me ayudan a mejorar mi nivel } \\
\text { de condición fisica. }\end{array}$ & 1 & 2 & 3 & $\begin{array}{lllll}4 & 5 & 6 & 78 & 9\end{array}$ & \\
\hline $\begin{array}{l}\text { El nivel de los programas y de los servicios de este centro deportivo es } \\
\text { excelente. }\end{array}$ & 1 & 2 & 3 & $\begin{array}{llllll}4 & 5 & 6 & 78 & 9\end{array}$ & 9 \\
\hline $\begin{array}{l}\text { El nivel de los programas y de los servicios de este centro } \\
\text { deportivo es muy alto. }\end{array}$ & & 2 & 3 & $\begin{array}{lllll}4 & 5 & 6 & 78 & 9\end{array}$ & 9 \\
\hline
\end{tabular}

\begin{tabular}{|c|c|c|c|c|c|c|}
\hline $\begin{array}{l}\text { El nivel de los servicios y la calidad de los programasde este } \\
\text { centro deportivo es muy alto. }\end{array}$ & $\begin{array}{|ll|}1 & 2 \\
\end{array}$ & 3 & 4 & 5 & $\begin{array}{lll}6 & 78\end{array}$ & 9 \\
\hline $\begin{array}{l}\text { Los programas y los servicios de este centro deportivo son de alto } \\
\text { nivel. }\end{array}$ & 1 & 3 & 4 & 5 & 678 & 9 \\
\hline $\begin{array}{l}\text { Los programas y servicios de este centro deportivo tienen un } \\
\text { gran valor. }\end{array}$ & \begin{tabular}{|ll}
1 & 2
\end{tabular} & 3 & 4 & 5 & 678 & 9 \\
\hline $\begin{array}{l}\text { Los programas y servicios de este centro deportivo merecen lo que } \\
\text { cuestan }\end{array}$ & 1 & 3 & 4 & 5 & $\begin{array}{ll}678 \\
\end{array}$ & 9 \\
\hline $\begin{array}{l}\text { Lo que consigo de este centro deportivo y lo que cuesta, me ofrece } \\
\text { valor. }\end{array}$ & 1 & 3 & 4 & 5 & $\begin{array}{ll}6 & 78\end{array}$ & 9 \\
\hline $\begin{array}{l}\text { En general, el valor de los programas y servicios en este centro } \\
\text { deportivo es alto. }\end{array}$ & \begin{tabular}{|ll}
1 & 2
\end{tabular} & 3 & 4 & 5 & 678 & 9 \\
\hline $\begin{array}{l}\text { Estoy satisfecho con los programas y servicios de este centro } \\
\text { deportivo. }\end{array}$ & 1 & 3 & 4 & 5 & 678 & 9 \\
\hline Soy feliz con los programas y servicios de este centro deportivo. & 1 & 3 & 4 & 5 & 678 & 9 \\
\hline $\begin{array}{l}\text { Estoy satisfecho de haber tomado la decisión de ser socio de } \\
\text { este centro deportivo. }\end{array}$ & 1 & 3 & 4 & 5 & $\begin{array}{ll}678 \\
\end{array}$ & 9 \\
\hline Mi decisión de ser socio de este centro deportivo fue acertada. & 1 & 3 & 4 & 5 & $\begin{array}{ll}678 \\
\end{array}$ & 9 \\
\hline $\begin{array}{l}\text { Realizaré comentarios positivos a un amigo acerca de los } \\
\text { programas y servicios de este centro deportivo. }\end{array}$ & 1 & 3 & 4 & 5 & 678 & 9 \\
\hline Si me preguntan, recomendaré este centro deportivo. & 1 & 3 & 4 & 5 & 678 & 9 \\
\hline $\begin{array}{l}\text { Continuaré participando en los programas de este centro } \\
\text { deportivo. }\end{array}$ & 1 & 3 & 4 & 5 & 678 & 9 \\
\hline $\begin{array}{l}\text { Me volveria a inscribir en este centro deportivo si me diera de } \\
\text { baja. }\end{array}$ & 1 & 3 & 4 & 5 & 678 & 9 \\
\hline
\end{tabular}




\section{B. Perfil socio - demográfico}

1. GÉNERO: Hombre Mujer

2. EDAD

3. FORMACIÓN ACADÉMICA

$\begin{array}{llll}\text { Primaria } & \text { Secundaria } & \text { Universitaria } & \text { Maestría }\end{array}$

Doctorado

4. OCUPACIÓN

Estudiante Funcionario Empleado empresa privada Independiente Desempleado

Otro

5. ESTADO CIVIL

Casado Soltero Otro

6. RANGO SALARIAL

1 Salario Mínimo

2-3Salarios Mínimos

4-5 Salarios Mínimos

Más

de 6 Salarios Mínimos

7. TIEMPO COMO USUARIO DEL CENTRO DEPORTIVO (EN AÑOS O MESES):

años;

meses

8. CUÁNTOS DÍAS REALIZA ACTIVIDAD FÍSICA POR SEMANA

9. TIEMPO DE DURACIÓN DE CADA SESIÓN DE ACTIVIDAD FÍSICA (EN HORAS) horas

10. ACTIVIDADES QUE REALIZA CUANDO ASISTE AL CENTRO DEPORTIVO

Actividades grupales (aeróbicos, yoga, Pilates, etc.)

Fitness

Otras

\section{GRACIAS POR SU COLABORACIÓN}

Para más información póngase en contacto con: Ángela Jaspóń Gómez Hincapié Grupo de Investigación en Gerencia del Deporte GIGEDE Universidad Tecnológica de Pereira Jasmin19@utp.edu.co 

Los gimnasios y centros de acondicionamiento físico (CAPFS) cumplen un papel muy importante en la promoción de la salud y prevención de la enfermedad física y psicológica de las personas, así como en el aprovechamiento del tiempo libre. Adentrarse en el conocimiento de los servicios que prestan y su funcionamiento técnico y administrativo, permite la caracterización sociodemográfica de sus usuarios y la identificación de la percepción que estos tienen de los servicios recibidos. Lo que tiene una alta correlación con la responsabilidad de las empresas del sector de la Actividad Física para prestar servicios y programas que cumplan con las expectativas del cliente y que sean satisfactorios según la relación costo/calidad para ellos y para la empresa.

En este contexto se ha desarrollado la investigación "Perfil del cliente de los gimnasios y centros de acondicionamiento físico caso Pereira", que tiene como objetivo evaluar la percepción del cliente en cuanto a calidad, valor, satisfacción e intenciones futuras en centros de fitness de Pereira (Gimnasios y CAPFS) (Colombia), y segmentarlos por características sociodemográficas y diferencias entre ellos.

En la primera parte se presenta el marco referencial de la investigación con el contexto legal que enmarca y regula la actividad física y los gimnasios y CAPFS en Colombia, y el referente contextual de los gimnasios participantes en la investigación; además, un marco teórico donde se desarrollan temas como: segmentación de centros deportivos y marketing, calidad de equipamientos e instalaciones, calidad de los programas y servicios, satisfacción de usuarios, valor del servicio abordado desde el marketing, y calidad de los colaboradores.

En la segunda parte, se presenta la metodología bajo la cual se desarrolló la investigación y los datos empíricos recolectados en los gimnasios y CAPFS, con lo que se da a conocer la situación actual del servicio, según la percepción de sus usuarios y el perfil del cliente.

ISBN: 978-958-722-402-3 